\title{
Nuevas aportaciones sobre el Campamento III de Renieblas (Soria): ¿castra de Nobilior o castra de Escipión?'
}

\section{New considerations on Renieblas Camp III (Soria): Nobilior's or Scipio's castra?}

\author{
FERNANDO MORALES HERNÁNDEZ \\ Dpto. de Prehistoria, Historia Antigua y Arqueología \\ Facultad de Geografía e Historia \\ Universidad Complutense de Madrid \\ Profesor Aranguren s/n - 28040 Madrid \\ fmorales@ucm.es \\ https://orcid.org/oooo-0002-7756-1848
}

\author{
ÁNGEL MORILLO CERDÁN \\ Dpto. de Prehistoria, Historia Antigua y Arqueología \\ Facultad de Geografía e Historia \\ Universidad Complutense de Madrid \\ Profesor Aranguren s/n. - 28040 Madrid \\ amorillo@ucm.es \\ orcid.org/0000-0003-2139-0346
}

\begin{abstract}
Resumen
La estrecha relación espacial y arqueológica del complejo de campamentos de Renieblas con la circumvallatio escipiónica de Numancia ha generado no poca controversia a lo largo de más de un siglo, derivada de la ausencia de estratigrafías. En el presente trabajo se apunta la posibilidad de que el antiguo Campamento III de la Gran Atalaya de Renieblas, atribuido por Schulten a la campaña de Nobilior de 153-152 a. C., fuera reocupado por Escipión Emiliano como campamento base en la campaña final contra la capital arévaca en el 134-133 a. C. La consideración y comparación de las defensas y estructuras interiores de Renieblas III y su anexo, así como la presencia de algunos materiales, especialmente los numismáticos, vienen a reforzar esta reocupación escipiónica. Esto nos lleva a plantear la hipótesis de que estaríamos ante un campamento legionario bifásico. Por otra parte, la observación a través del análisis de los datos LiDAR nos ha permitido completar el trazado del mencionado anexo del Campamento III por el suroeste.
\end{abstract}

Palabras clave: Arqueología Militar Romana, Hispania, Campamentos romanos, Numancia, Renieblas, Escipión Emiliano, datos LiDAR

\section{Abstract}

The spatial and archaeological connection between the Renieblas camp complex and the Numantia scipionic circumvallatio has generated considerable controversy over more than a century due to the absence of stratigraphic analysis. The present study identifies the possibility that the former Camp III of the Gran Atalaya of Renieblas, originally attributed to the Nobilior campaign of 153-152 BC by Schulten, was reoccupied by Scipio Aemilianus as a base camp in the final campaign against the Arevaci capital in 134-133 BC. This statement is reinforced when considering and comparing the defences and internal constructive features of Renieblas III and its annex, as well as the presence of some materials, especially numismatic finds. This leads us to hypothesize a biphasic legionary camp. On the other hand, analysis of available LiDAR data has allowed us to complete the layout of the aforementioned Camp III annex through the southwest.

Key words: Roman military Archaeology, Hispania, Roman Camps, Numancia, Renieblas, Scipio Aemilianus, Airborne LiDAR technology

1 Este trabajo se inscribe dentro del Proyecto de Investigación «Paisaje y territorio militarizado en la Hispania romana: movilidad y transferencia cultural (ss. II a.C.-IV d.C.)» (I+D HAR2017-85929-P), concedido por el Ministerio de Economía, Industria y Competitividad (MINECO), la Agencia Estatal de Investigación (AEI) y el Fondo Europeo de Desarrollo Regional (FEDER), cuyos investigadores principales son Ángel Morillo y Cruces Blázquez Cerrato. Agradecemos a C. Pereira su ayuda con el tratamiento de imágenes LiDAR y Google Earth.

Durante la evaluación de este trabajo ha fallecido nuestro colega y amigo Joaquín Gómez-Pantoja, buen conocedor de la antigüedad en las tierras sorianas y en particular del complejo militar de Numancia. Vaya desde estas páginas nuestro recuerdo a su memoria. 
1. Los campamentos de Renieblas. Problemas de datación e interpretación

Las visitas realizadas por Schulten en 1908 al cerro «Talayón» de Renieblas (rebautizado por Schulten como «Gran Atalaya» por problemas de traducción), yacimiento ubicado a unos $8 \mathrm{~km}$ al este de la ciudad de Numancia (figura I), descubrieron restos de muros que, como cuenta él mismo, eran reconocibles a flor de tierra. Esta circunstancia le permitió levantar los primeros planos. Entre 1909 y I9I2 se realizaron extensas excavaciones en las que se identificaron restos de cinco campamentos romanos parcialmente superpuestos que se extendían por toda la ladera de la colina. Los resultados parciales se dieron a conocer en diversas publicaciones (Schulten, I9II, I9I4, I928, I945) mientras que en 1929 se publica una gran monografía en alemán (Schulten, 1929). En las excavaciones se limitaba a seguir el trazado de los muros, sin tener en cuenta las estratigrafías. Sus dataciones se basaban principalmente en las indicaciones proporcionadas por los textos clásicos sobre el periodo de la conquista de la antigua Hispania, unidas, eso sí, a una gran intuición. La excavación propiamente dicha del asentamiento tenía una importancia secundaria, destinada a confirmar la atribución erudita del «arqueólogo». Schulten constituye por lo tanto uno de los máximos representantes de la «arqueología filológica» en la península ibérica (Morillo, 2008: 83-84). El sistema de excavación basado en el seguimiento de muros provocó que no se asociaran directamente las diferentes estructuras exhumadas a los distintos contextos estratigráficos y materiales, lo que ha impedido llegar muy lejos en la constatación de la documentación obtenida. Este método arqueológico se encuentra en el origen de buena parte de los problemas que aquejan todavía hoy en día al conocimiento de los campamentos numantinos en su conjunto (Morillo y Morales, 2015: 282).

A partir de la búsqueda en las fuentes clásicas de las referencias de la presencia de Roma en Numancia o su territorio, Schulten relacionó los Campamentos I y II con la campaña de Catón en 195 a. C., pero no explica el motivo de la construcción de los dos campamentos el mismo año y en el mismo lugar (Morillo, I991: 153). Para el investigador alemán, el primero de ellos, con planta irregular de tendencia poligonal presentaba una superficie de I2 ha, estando delimitado por un muro de piedra de 2 a $2,5 \mathrm{~m}$ de espesor, y estaba jalonado por torres cuadrangulares interiores. Las construcciones interiores estaban dotadas de zócalos pétreos, motivo que llevó a Schulten a plantear que sería un campamento de invierno (Schulten, I929: 33-39). Muy semejante es el recinto II, también irregular y rodeado por una muralla de unos $2 \mathrm{~m}$ de anchura, con torres adosadas, del que se conserva menos de la mitad de su perímetro. En este caso Schulten plantea que sería un campamento de verano ante la aparente carencia de estructuras interiores de piedra (Schulten, 1929: 39-40). Sin embargo, el único argumento para la datación de ambos recintos es la mención de Aulo Gelio (I6. I. 3) de una conversación de Catón donde el cónsul menciona que, al regreso de su viaje al valle del Ebro desde la Meseta, se detuvo junto a Numancia. Incluso recientemente, Luik apunta que la datación de Renieblas II está totalmente abierta (Luik, 2002b: 77r; Jiménez, Bermejo, Liceras, Moreno y Tardio, 20I8).

De cualquier manera, las evidentes semejanzas constructivas entre ambos, tanto en lo relativo a la planta como a la tipología y sistema constructivo de defensas y puertas nos indican una cronología muy cercana en el tiempo (Dobson, 2008: 385).

El Campamento III es también poligonal, de 49 ha, con un anexo o prolongación hacia el sureste Más adelante nos ocuparemos con detalle de este recinto. Schulten lo considera unos castra hiberna del año I53-I52 a. C. partiendo de un texto de Apiano (Iber. 46-47) en el que afirma que el cónsul Nobilior levantó su campamento a 24 estadios de Numancia, distancia que grosso modo se corresponde con los casi $8 \mathrm{~km}$ que separan Renieblas de la ciudad arévaca (Schulten, I929: 4I; Morillo, I991: 153; Luik, 2002b: 772).

Finalmente, los Campamentos IV y V, responden a un modelo constructivo bien diferente. El primero es rectangular con esquinas en ángulo recto, con una extensión de 58,9 ha. Está protegido con muros de piedra sin torres de unos $3 \mathrm{~m}$ de espesor, con tituli frente a las puertas y un supuesto braquion protegiendo el acceso al río Merdancho. Schulten lo interpreta como un campamento de verano edificado en el 74 a. C. por $\mathrm{Cn}$. 


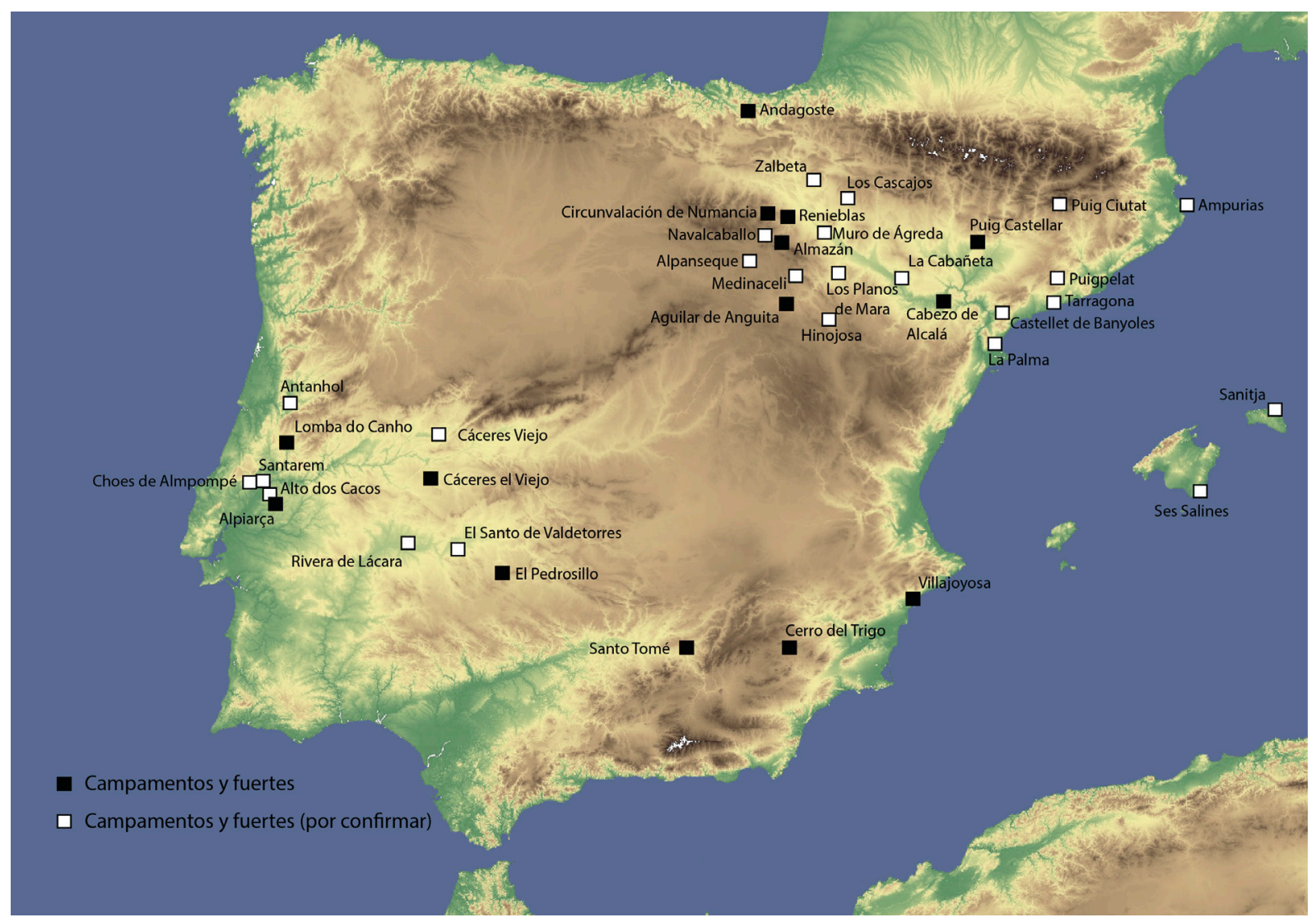

Figura 1. Campamentos republicanos en Hispania (A. Morillo)

Figure 1. Late Republican Roman Camps and Forts (A. Morillo)

Pompeyo (I929: 137-I45). Dobson, sin más argumento que las referencias textuales a la presencia de tropas romanas en esta zona, no descarta que pudiera pertenecer a Q.Pompeyo Aulo (I4r a. C.) y C. Hostilio Mancino (137 a. C.) (2008: 386-387).

Por lo que se refiere a Renieblas V, presenta una morfología muy semejante, extendiéndose en este caso por una superficie de 6I, 2 ha. Sus murallas presentan $4 \mathrm{~m}$ de espesor, ampliándose en algunas zonas hasta los 4,5 m. Están construidas mediante un doble paramento de piedras trabadas con argamasa y cuenta con torres interiores rectangulares de 5-6 m de anchura. Se conservan los cimientos pétreos de las construcciones interiores (contubernia, horreum), lo que lleva a Schulten a considerarlo unos castra biberna pompeyanos, del invierno del 75/74 a. C. (I929: I46-I55) (figura 2).

Las carencias metodológicas de Schulten y su excesiva dependencia de las fuentes clásicas ya llevaron a alguno de sus colegas a plantear, en el mismo momento en que se conocieron los primeros resultados, serias objeciones a las cronologías del investigador alemán. Este sería el caso de Fabricius (I9II), quien situaba la principal ocupación del conjunto en época de Escipión. Mucho tiempo después, Hildebrand (1979), estudiando las monedas, los lleva a ese mismo momento. Aunque sus conclusiones son muy discutidas, algunos autores asumieron sus dataciones, llevando a la cronología de determinados materiales a esa época (Romero, 1990; Sanmartí, 1992; Jimeno y Martín Bravo, 1995; Jimeno, 2002), incluyendo los de los dos últimos recintos (Hildebrandt, I979: 266-271; Sanmartí, 1992: 427-428). Otros investigadores apoyan fechas que giran en torno al tránsito entre el siglo II y i a. C. (Pamment Salvatore, I996; Morales y Dobson, 2008). Finalmente, en los últimos años se abre camino la confirmación a la datación de los dos últimos recintos durante el conflicto sertoriano, a partir de la publicación y reinterpretación de materiales (Luik, 2002a; Gómez-Pantoja y Morales, 2002, 2008) o la técnica de castramentación (Morillo, Morales y Durán, 2017: 194; Morillo y Sala, 2019: 56). 


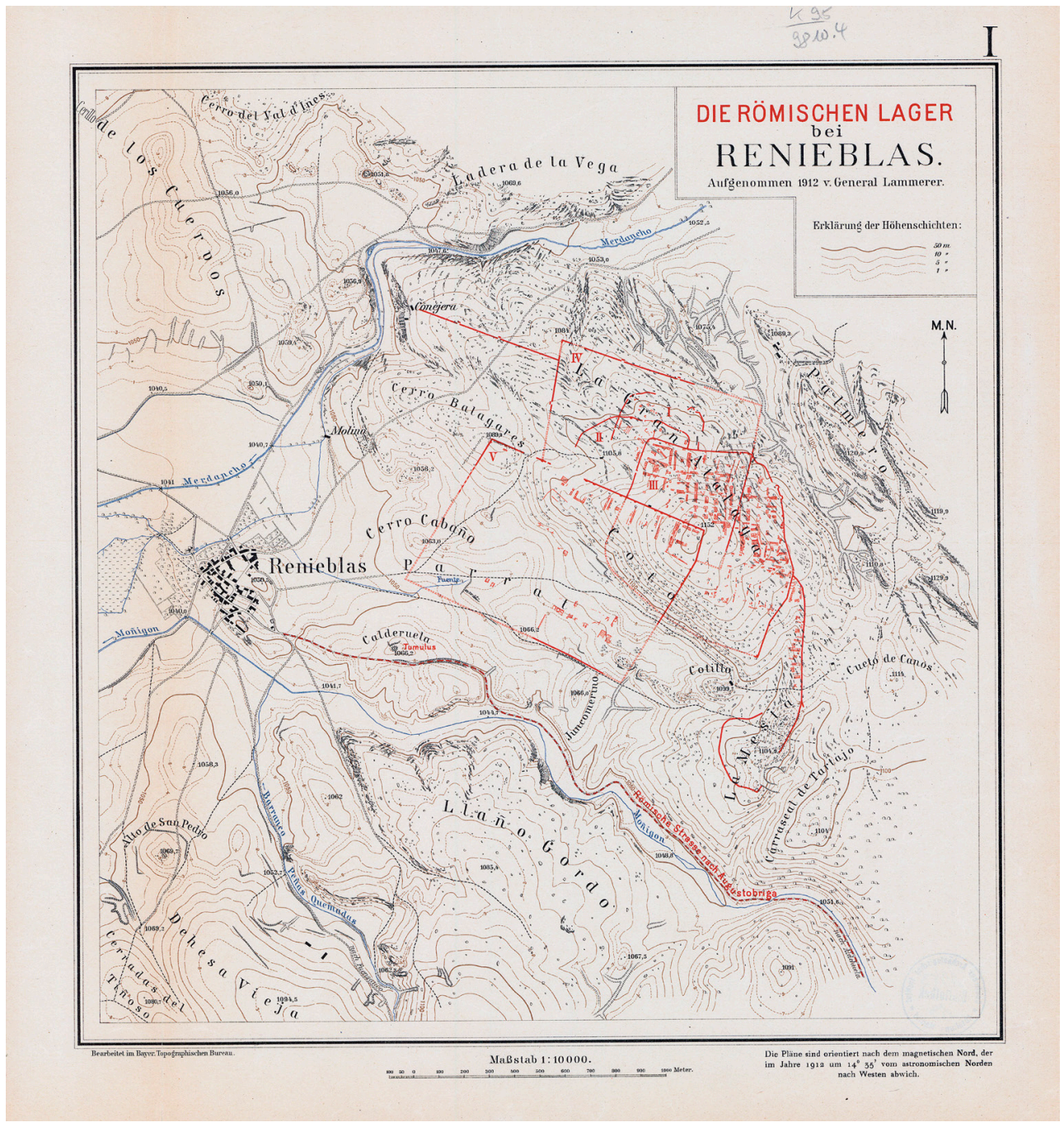

Figura 2. Planimetría general de la Gran Atalaya de Renieblas con los campamentos (Schulten 1929: lám. I)

Figure 2. Gran Atalaya de Renieblas. General plan of Roman Camps (Schulten, 1929: Plate II)

Como se puede comprobar, a día de hoy todos los campamentos de la Gran Atalaya plantean problemas de cronología, a excepción del Campamento III, que se suele atribuir sin discusión a la campaña de Nobilior. Pero también sobre esta cuestión cada vez existen más dudas. No deja de llamar la atención el hecho que, a juzgar por las dataciones de Schulten, ninguno de los cinco recintos superpuestos sería coetáneo al cerco de Numancia, a pesar de las indudables similitudes de Renieblas III en cuanto a sistemas constructivos y registro material respecto a los campamentos y fuertes escipiónicos. Existen cada vez más indicios para pensar que este campamento estuvo en funcionamiento durante el asedio y toma de Numancia por parte de las tropas de Escipión en el año I33 a. C.
2. El Campamento III de Renieblas a través de la interpretación de Schulten del relato de las fuentes clásicas

E1 historiador griego Apiano, en su Historia Romana nos ha legado un texto extenso sobre la guerra de Numancia. Dejando al margen el razonable grado de certidumbre del relato como consecuencia de la utilización de fuentes bien informadas, destaca la pobreza de detalles. A pesar de estas limitaciones, el texto de Apiano sobre la guerra de Numancia es la fuente exclusiva para esta parte de la historia, lo que hizo afirmar a Schulten que es «una de las más sugestivas y exactas relaciones que poseemos de una guerra de la antigüedad» (1945: 54). 
El relato de Apiano contiene la referencia fundamental empleada por Schulten para datar Renieblas III. En Iber. 46, Apiano relata cómo Nobilior, tras la derrota del 23 de agosto de 153 a. C. frente a arévacos y belos en la ruta desde el valle del Jalón hacia la meseta superior, se acerca Numancia tras haber recibido refuerzos de jinetes númidas y elefantes:

Por consiguiente, los arévacos se reunieron de inmediato en esa misma noche en Numancia, que era la ciudad más poderosa, y eligieron como generales a Ambón y Leucón. Nobilior, a su vez, tres días más tarde marchó contra ellos y fijó su campamento a una distancia de veinticuatro estadios $(\text { Iber. } 46)^{2}$.

Algo más adelante, Apiano continúa su relato:

Nobilior, perdidas las esperanzas totalmente, invernó en su campamento guareciéndose como le fue posible $(\mathrm{Iber} .47)^{3}$.

De estos dos pasajes se desprende en primer lugar, la instalación de los castra de Nobilior a 24 estadios de Numancia, es decir, casi 5 kilómetros, lo que a grandes rasgos se correspondería con los poco más de ocho kilómetros que separan Numancia del Talayón de Renieblas, aunque no se da ninguna otra referencia. Schulten demostró con sus excavaciones que el tamaño del Campamento III, 49 ha era el apropiado para un ejército consular de dos legiones con organización manipular y sus aliados. Además, Nobilior adecuó el campamento para pasar allí el invierno (figura 3 a y 3 b).

Algunos materiales también le sirvieron para corroborar la adscripción del Campamento III a Nobilior, entre los que destaca el propio investigador la numismática y una marca anfórica, muy similar a otra encontrada en los niveles de destrucción de Cartago, fechados en el año I46 a. C. (Schulten, I929: I06).
Apiano cuenta que en el I4I a. C. Pompeyo instaló su campamento ( $\pi \alpha \rho \alpha \sigma \tau \rho \alpha \tau o \pi \varepsilon \delta \varepsilon v ́ \omega v)$ junto a Numancia (Iber. 76), pero no da ninguna referencia más. Posiblemente a finales de verano, Pompeyo volvió contra Numancia (Iber. 78). Apiano no hace ahora ninguna referencia, como había hecho anteriormente, sobre dónde acampó Pompeyo. Es de suponer que en el mismo lugar donde lo había hecho la primera vez, es decir, y siguiendo a Schulten, en Castillejo (1927: I72). Pero no hay más evidencias de dicho acantonamiento, más allá de que se realizó a cielo abierto.

Un poco más adelante, Apiano narra la corta y aciaga campaña de C. Hostilio Mancino, cónsul en 137 a. C., donde se menciona el viejo campamento de Nobilior:

Al propalarse el rumor de que los cántabros y vacceos venían en socorro de los numantinos, paso toda la noche, lleno de temor, en la oscuridad sin encender fuego y huyó a un descampado que había servido, en cierta ocasión, de campamento a Nobilior (Iber. 80) $)^{4}$.

De dicho pasaje se deduce que Mancino tenía instalado su campamento muy cerca de la ciudad, en una innegable proximidad visual, lo que se deduce del hecho de no encender fuego durante la noche; en un segundo momento, huye a un lugar abandonado (descampado) donde había estado el acantonamiento de Nobilior, sin duda la Gran Atalaya de Renieblas. Schulten localiza el primero de estos recintos en el identificado con su «fase azul» del fuerte del Castillejo (I927: I72). Nada apuntan las fuentes respecto al tiempo que Mancino estuvo en el antiguo campamento de Nobilior ni de sus movimientos. Los textos parecen sugerir que al menos un cierto tiempo y hay que pensar que Mancino tuvo que

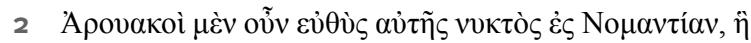

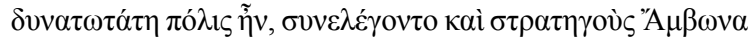

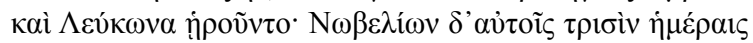

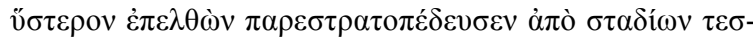

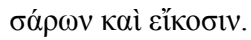

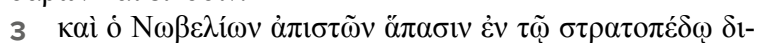

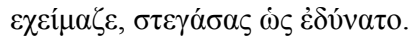

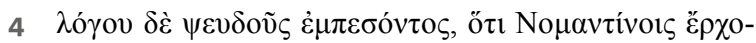

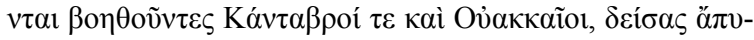

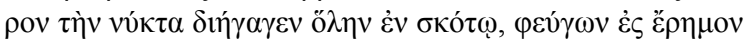

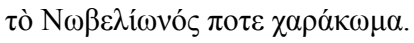



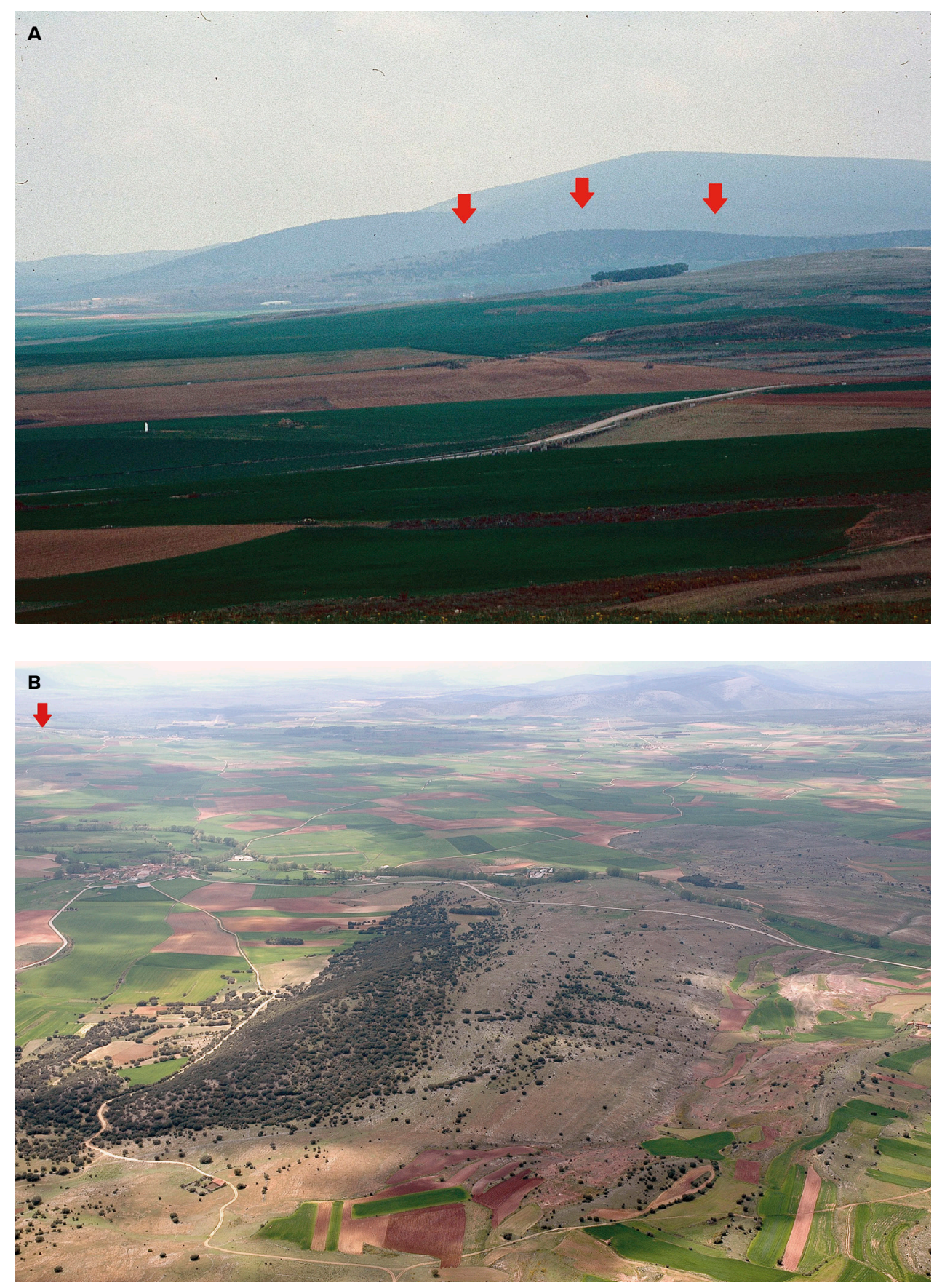

Figura 3. A. Ubicación de la Gran Atalaya de Renieblas desde la ciudad de Numancia (A. Morillo, 1996); B. Localización de Numancia desde la colina de Renieblas (F. Didierjean, 2008)

Figure 3. A. Localization of La Gran Atalaya de Renieblas from Numancia (A. Morillo, 1996);

B. Localization of Numancia from Renieblas (F. Didierjean, 2008)

esperar en este recinto las noticias de Roma y la llegada de su sucesor, el cónsul Emilio Lépido. Lo que sí dice Apiano es que una vez aquí Lépido, al frente del campamento, se impacientaba esperando las decisiones de Roma, y no soportaba la inactividad, lo que de nuevo está refrendando la prolongada estancia de tropas romanas en el campamento de Nobilior.
Aunque las fuentes clásicas no vuelven a citar el campamento de Nobilior, tres pasajes de Apiano ofrecen cierta evidencia circunstancial de que el despliegue de Escipión frente a Numantia pudo servirse de las ventajas tácticas que ofrece el Talayón, y que, por tanto, es posible situar con un grado razonable de certeza a las tropas del Numantino en Renieblas. 
$\mathrm{Al}$ parecer, justo antes de la llegada de Escipión en el I34 a. C., el ejército se encontraba acampado en Carpetania, donde lo había dejado Calpurnio Pisón:

Elegido contra ellos Calpurnio Pisón no realizó ningún intento contra Numancia, sino que hizo una incursión contra el territorio de Pallantia y, tras haberlo arrasado un poco, pasó el resto de su mandato en sus cuarteles de invierno en Carpetania $(\text { Iber. } 83)^{5}$.

Allí se le incorporó Escipión, ya que Apiano (Iber. 84) dice:

A todos ellos, que en total eran unos cuatro mil, los puso bajo el mando de su sobrino Buteón, y él, con unos pocos, se adelantó hacia Iberia para unirse al ejército $[\ldots]^{6}$.

Y después de llegar inició toda una serie de reformas y maniobras de entrenamiento (Iber. 85 y 86).

Contrariamente, Schulten sugiere que «seguramente» el ejército se desplazó a Tarraco para recibir a su nuevo comandante (1945: I34), y que las maniobras de entrenamiento se desarrollaron en los llanos de Urgel y la región de Ilerda (I937: 70), o en las amplias llanuras del Ebro central, es decir, en la comarca de Turiaso (Tarazona) y Augustobriga (Muro de Agreda), que se hallaba en la ruta hacia Numancia (Schulten, I945: I38-I40). Sin embargo, Apiano no menciona ningún movimiento de las tropas en este momento, por lo que hemos de pensar que fue el propio Escipión quien se incorporó al ejército, y no en Tarragona, sino en Carpetania, lo que ya fue sugerido por Capalbo (1996: 183) y corroborado recientemente (Morales, 202I).

En Iber. 87 Apiano relata que solo cuando Escipión consideró que el ejército estaba suficientemente preparado, se traslada «cerca» ( $\dot{\alpha} \gamma \chi 0 \bar{v})$ de los numantinos:
Cuando calculó que el ejército estaba presto, obediente a él y capaz de soportar el trabajo, trasladó su campamento a las cercanías de los numantinos ${ }^{7}$.

Apiano no dice explícitamente cuánto de cerca estaba de Numancia, ni cómo se instaló, pero parece evidente que levantó un campamento. Este acercamiento debió producirse quizá a comienzos de verano (¿principios de junio?), pues, ya instalado en su campamento ( $\tau \circ v \sigma \tau \rho \alpha \tau o \pi \varepsilon ́ \delta o v)$, «Recorrió, en busca de forraje, toda la zona situada detrás (ó $\left.\pi^{\prime} \sigma \omega\right)$ del campamento, y segó el trigo todavía verde» (Iber. 87). Y de igual modo, en Iber. 89 Apiano refiere cómo Escipión, tras la incursión por tierras vacceas con el propósito de cortar el suministro a los numantinos, regresó a la región de Numancia:

Mientras atravesaba el territorio de los cauceos, cuyo tratado había violado Lúculo, les hizo saber por medio de un heraldo que podían regresar sin peligro a sus hogares. Y prosiguió hasta el territorio de Numancia para pasar el invierno ${ }^{8}$.

En ambos textos, tanto en su primera llegada a territorio numantino, como en su regreso de tierras vacceas, parece sugerirse que Escipión se mantuvo a una distancia prudencial de Numancia, «en las cercanías» (ó $\rho \chi o v ́)$ de los numantinos, observando el desarrollo de la guerra, esto es, desde el punto de vista táctico lo suficientemente cerca como para controlar los movimientos en la ciudad pero suficientemente lejos como para representar un peligro directo que motivara un movimiento hostil por parte de estos antes de tiempo. Pero nada nos dice Apiano del lugar concreto de acantonamiento.

Esta posición «cercana» contrasta con el término griego empleada por Apiano algo más adelante (Iber. 90), donde cuenta cómo Escipión instala dos

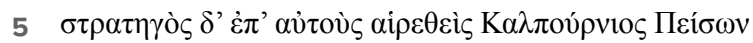

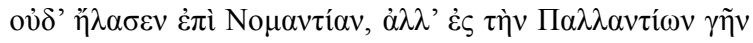

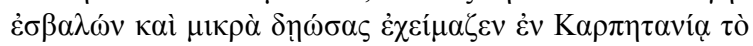

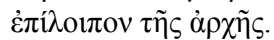

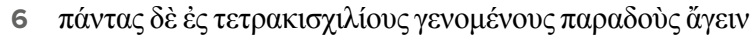

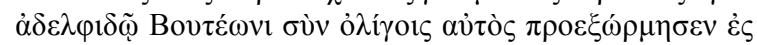

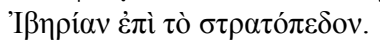

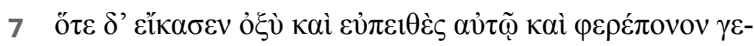

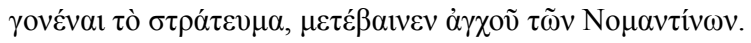

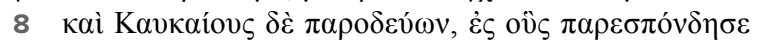

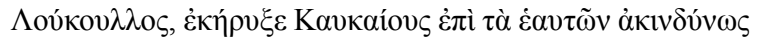

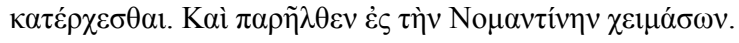


campamentos a poca distancia de la ciudad indíge-

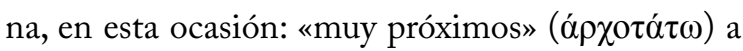
Numancia con los que se inicia la circunvalación, sin duda Peña Redonda y Castillejo.

No mucho después, estableció dos campamentos muy próximos a Numancia y puso al frente de uno de ellos a su hermano Máximo, en tanto que él en persona se encargaba del otro 9 .

Schulten por el contrario, a pesar del silencio de las fuentes y de los matices del propio Apiano que aquí resaltamos, considera que directamente Escipión se situó ante Numancia en los campamentos de Castillejo y Peña Redonda, lo que contrastaría con el pasaje anterior donde se indican dos momentos cronológicos («No mucho después [...]») y dos ubicaciones diferentes, sugeridas por el empleo de los términos «cerca» $\mathrm{y}$ «muy cerca». Evidentemente la interpretación de Schulten fuerza los datos de las fuentes al no recoger la secuencia de acontecimientos.

Acudiendo una vez más al texto griego original, resulta muy curioso ver también cómo Apiano, en la primera llegada de Escipión ante Numancia, antes de la expedición a tierras vacceas, emplea el término $\sigma \tau \rho \alpha \tau$ ó $\pi \varepsilon \delta o v$ para referirse en varias ocasiones al campamento de Escipión, y cómo tras regresar de la expedición, utiliza el término $\chi \alpha \rho \alpha ́ \kappa \omega \mu \alpha$, lo que indica de nuevo dos realidades diferenciadas (Morillo y Morales, 2015: 280).

Esta contradicción de la interpretación de Schulten respecto a las fuentes ya fue sugerida durante las excavaciones por Fabricius (I9II), si bien este opinaba que los campamentos de Escipión eran el IV y el V, cuestionando la cronología sertoriana que Schulten les había asignado. Fabricius sugiere que el Campamento IV podría haber sido el campamento de verano de Escipión de 134 a. C., mientras que el Campamento V, coincidiendo con Schulten en su excelente construcción, sería uno de los dos campamentos de invierno que Escipión

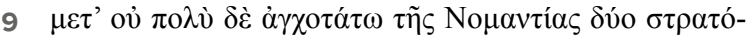

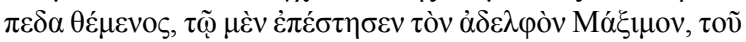

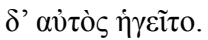

construyó para I34/133 a. C., donde se iniciaron los preparativos del asedio y desde donde podía observarse Numancia «cerca» (I9II: 370-382).

\section{El campamento de Renieblas III: arquitectura defensiva y urbanismo interior}

Tal y como ya hemos apuntado, las estructuras constructivas correspondientes a este recinto fueron exhumadas entre I909 y I9I2. Al ser el mejor conservado, es sin duda objeto de una mayor atención en la monografía correspondiente (Schulten, 1929: 4I-I36).E1 investigador alemán, llevado por las referencias de Apiano (Iber. 46 y 47), no duda en ningún momento de su cronología, lo que le lleva a intitular el capítulo correspondiente como «Lager III. Das Lager des Konsuls Nobilior I53 v. Chr.», apartándose formalmente de la forma en que presenta los otros cuatro campamentos, sin cronología establecida.

La forma general del campamento es poligonal de tendencia cuadrada, adaptándose a la topografía (pendiente y características del terreno), con dos de las esquinas redondeadas y la tercera (sureste) en ángulo recto. Se conservan completos los lados norte y este, así como la mitad meridional del lado oeste (figura 4 ). Se ha perdido toda la parte sur del lado occidental y todo el costado meridional, aunque Schulten propone una reconstrucción de su perímetro siguiendo aproximadamente la curva de nivel correspondiente a los I $090 \mathrm{~m}$ de altitud (I929: 47). Esto le lleva a calcular una superficie ocupada de unas 49 ha, con lados mayores en torno a 700 $\mathrm{m}$, lo que indicaría que fue concebido con una superficie de $20 \times 20$ actus, es decir, de 710,4 $\times 710,4 \mathrm{~m}$ (I929: 42). Estas medidas se adaptan perfectamente a un campamento para dos legiones con organización manipular y sus aliados, que responde al esquema descrito por Polibio de un campamento legionario para un ejército consular de dos legiones, hecho excepcional dentro de los campamentos republicanos (Dobson, 2008: 68-I2I). Sin embargo, las medidas reales son más irregulares de las que indica Schulten para el urbanismo interior $(970 \times 730 \mathrm{~m})$. La reconstrucción de Schulten de todo el sector meridional 


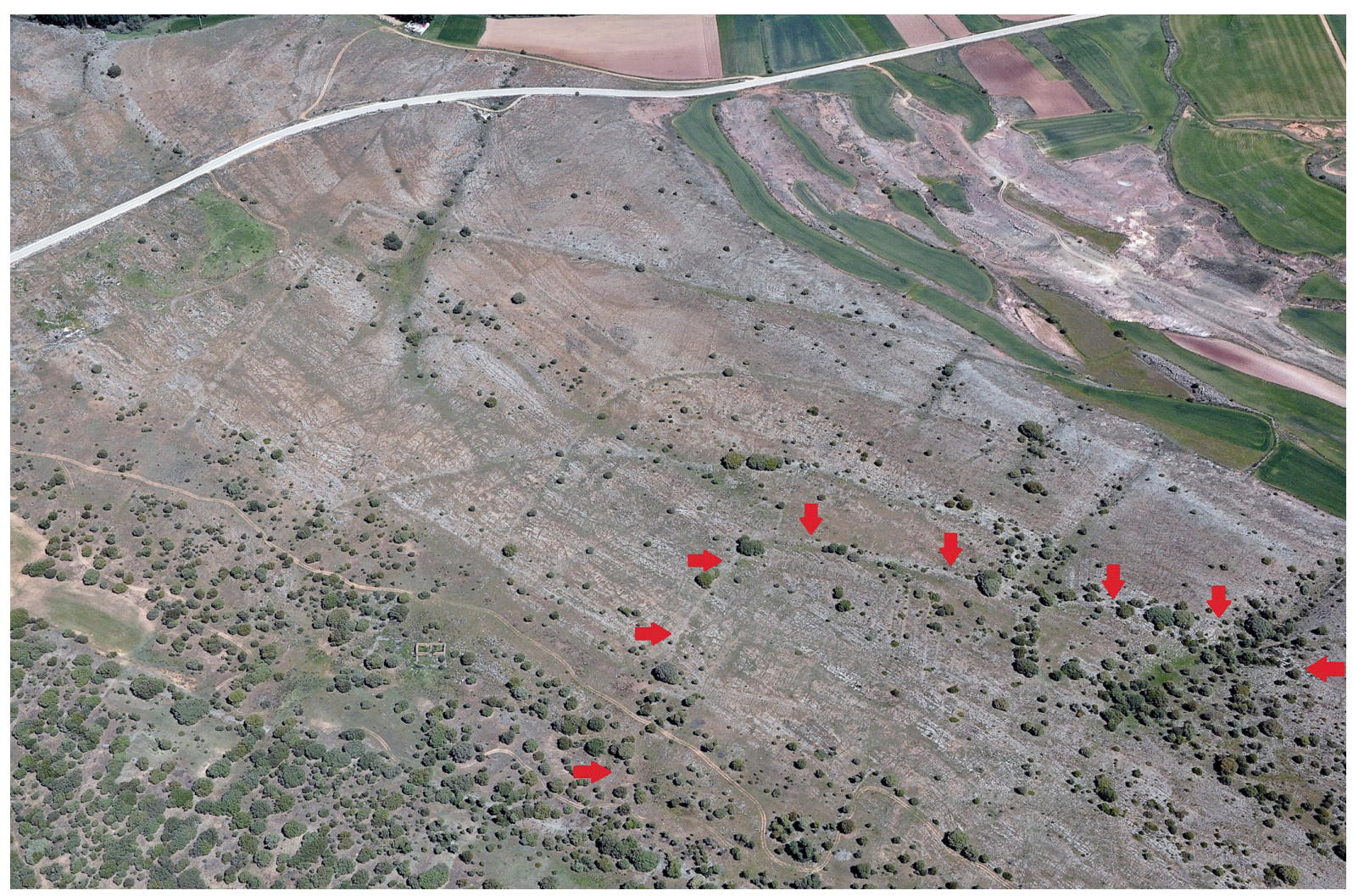

Figura 4. Vista aérea de la zona central del conjunto de campamentos donde se aprecian varios recintos. Las flechas indican la esquina noroeste del Campamento III. (Fotografía F. Didierjen 2008, con modificaciones)

Figure 4. Aerial view of the central area of the complex of Camps of Renieblas. Arrows show the northwest corner of Camp III (F. Didierjean, 2008, with modifications)

desaparecido no deja de ser hipotética y muy imaginativa, ya que no hallaron restos de muralla o construcciones interiores. Ni siquiera pudo posicionar la esquina suroeste. De hecho, dentro de la misma publicación, dicha esquina aparece redondeada en alguna de sus reconstrucciones (Schulten, I929, lám. I) y en ángulo recto en otras (Schulten, 1929, lám. IV). La extensión del campamento en la fuerte pendiente meridional del cerro planta no pocos problemas topográficos.

El recinto de Renieblas III está delimitado por una fuerte muralla de piedra de $4 \mathrm{~m}$ de anchura, aunque en algunos tramos llega a $5 \mathrm{~m}$ de espesor, construida mediante dos paramentos irregulares, de unos $0,40 \mathrm{~m}$ de anchura, el interior, y o,70 m, el exterior. Dicha muralla, al igual que el resto de los campamentos de La Gran Atalaya, carece de fosas de fundación y cimientos y se apoya directamente en la roca madre (Schulten, I929: 24). Las dos o tres hiladas que sacaron a la luz las excavaciones de Schulten presentaban un aparejo irregular realizado con grandes bloques de piedra calcárea, que alcanzaban algunos los $2 \mathrm{~m}$ de largo por $\mathrm{I} \mathrm{m}$ de alto. Entre ellos, siguiendo la técnica de emplecton, se colocó un relleno de piedras más pequeñas y tierra (Schulten, 1929: 50-5I). En algunos lugares se detectó un muro central paralelo a los paramentos externos a manera de espina dorsal, que compartimenta en dos módulos diferentes el sistema constructivo interior de la muralla, destinado sin duda a darle una mayor solidez y permitir una mayor altura. Schulten relaciona este tipo de obra con la documentada en algunos tramos de la circunvalación cerca de Peña Redonda y Dehesilla (I929: 5 I). Dobson duda de su empleo en este Campamento III (2008: 134). Schulten proyecta la altura de la muralla hasta unos $3 \mathrm{~m}$ (figura 5).

Según Schulten se conservaban 27 torres a lo largo de la muralla, 16 de ellas intermedias adosadas a su paramento interior, dos bastiones semicirculares que sobresalían de la muralla al noreste (torres i6 y i7) y seis asociadas a puertas. La separación entre torres 


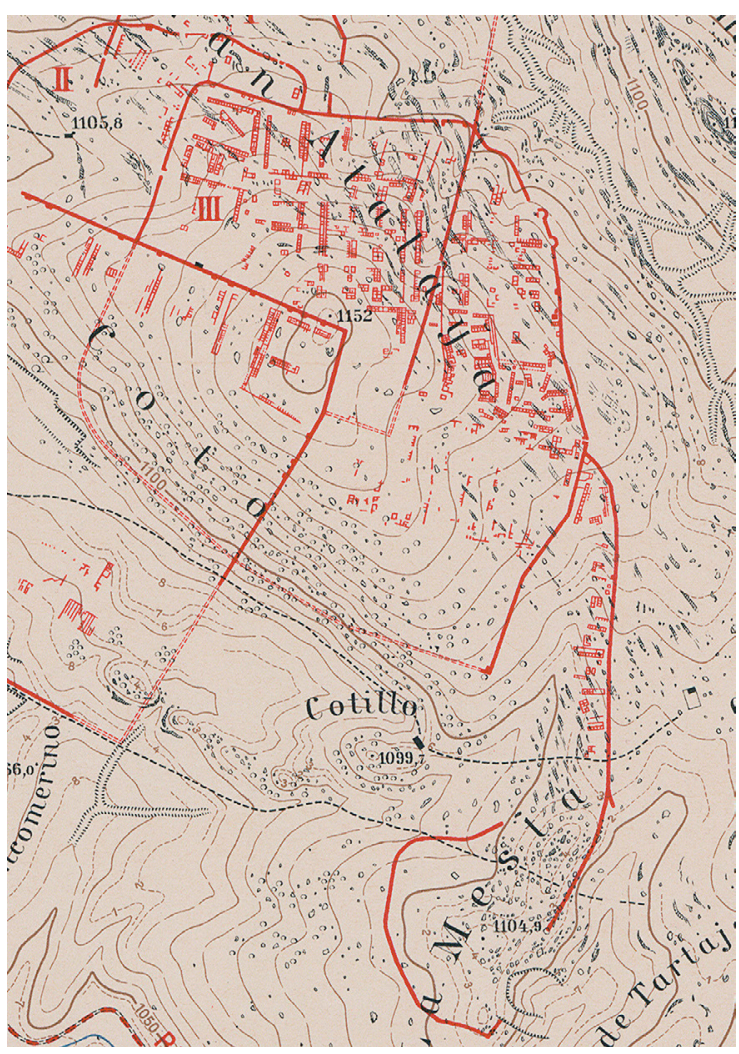

Figura 5. Planimetría del Recinto III de Renieblas con su Anexo al sureste (Schulten 1929: lám. I, detalle)

Figure 5. General plan of Camp III of Renieblas and the Annexe (Schulten, 1929: Plate I, detail)

no es regular ni se ajusta a ninguna medida estandar, variando entre I4 y $220 \mathrm{~m}$, aunque creyó poder detectar un patrón de roo pies romanos, unos $29 \mathrm{~m}$, por la separación entre algunas torres (1929: 52 y 56 ). El tamaño de estas oscila entre 2 y $6,5 \mathrm{~m}$ de proyección respecto a la línea de la muralla, y entre 3 y $7 \mathrm{~m}$ de anchura (1929: 52). En realidad, las 16 torres adosadas al interior de la muralla por su lado más corto presentan módulos muy semejantes, alrededor de $3 \mathrm{~m}$ de longitud por 2,5-2,8 $\mathrm{m}$ de anchura. Estructuralmente se identifican como tales por su yuxtaposición a la cara interna de la muralla y su morfología rectangular, pero al no conservarse sus alzados tenemos serias dudas de que no estemos ante plataformas macizas para ascender al parapeto de la muralla a través de escalones. La presencia de rampas o terraplenes adosados a la obra de la muralla que conducen a las mencionadas «torres» así parece confirmarlo (I929: lám. 8, г y 2). El propio Schulten llega a dudar de si no estamos ante letrinas más que ante torres (I929: I35).
Se encontraron tres puertas, dos en el lado norte y una en el lado este, y quizá testimonio de una cuarta puerta en la muralla occidental (Schulten, I929: 57). Las puertas son muy similares en la forma, ya que todas estaban flanqueadas por sendas torres grandes de un módulo que duplica el de las situadas a intervalos. La puerta principalis dextra presenta incluso cuerpo de guardia. La anchura de los accesos oscila entre 2,60 m (porta principalis dextra) y 4,80 m (porta quintana dextra) (Schulten, 1929: 57). Schulten sugiere que el hueco del lado oeste podría ser una puerta, ya que lleva asociada en su lado norte la torre I, falta una torre al otro lado del hueco para producir un diseño similar al hallado en las otras puertas (1929: 57).

Uno de los aspectos más llamativos de este campamento es que, al igual que el resto de recintos de Renieblas y el cerco numantino, carece de foso. Schulten lo atribuye a la naturaleza del terreno rocoso (1927: 84-85; 1929: 51). Dobson se inclina a pensar que es un problema de documentación arqueológica por parte del investigador alemán (2008: 123). Sin embargo, cada vez conocemos más ejemplos de la existencia de recintos militares del siglo II a. C., como El Pedrosillo, que se apartan del modelo canónico de agger polibiano (Morillo, 20I6: 20-23; Morillo et alii, 20II).

Las dimensiones del intervallum varían en general entre 25 y $29 \mathrm{~m}$ es decir, en torno a los 90 pies romanos, si bien en ocasiones se reduce a tan solo $5 \mathrm{~m}$, lo que está muy lejos de los 240 pies romanos canónicos mencionados por Polibio como anchura para este espacio (Schulten, 1929: 59-60).

Por lo que se refiere al urbanismo interno, son perfectamente reconocibles la mayor parte de las estructuras en torno a la via principalis y a la via quintana, que corresponde a toda la parte norte del campamento. En un lugar central se levantan praetorium, forum y quaestorium, rodeados por barracones de tropa, organizados en hileras regulares de $22 \mathrm{~m}$ (norte-sur) 9 × 39-40 m(este-oeste), algunos de ellos, junto a las defensas, dispuestos en triples bloques unidos por sus lados cortos. Los contubernia miden en torno a $4 \mathrm{~m}$ de lado (Schulten, I929: 6I-III). A Schulten le llama la atención la posición del praetorium, que gira respecto a la orientación de todo el conjunto para afrontarse justamente al suroeste, hacia 
Numancia (1929: 98-99). Dobson, que ha reinterpretado de forma pormenorizada el conjunto, da por válidas la mayoría de las hipótesis del investigador alemán, aunque cuestiona la forma del praetorium y la posición del forum y quaestorium, además de proponer interesantes cuestiones sobre la forma y disposición de los barracones, haciendo hincapié en que parecen corresponder a una estructura del ejército manipular, previa al empleo de cohortes (2008: 186 y 187).

\section{El anexo del Campamento III o Campamento VI. Novedades y nuevos planteamientos}

En la parte oriental de la muralla del Campamento III, Schulten identificó los restos de otra muralla que arrancaba cerca de la puerta oriental de este recinto tomando dirección sur en paralelo a las defensas del recinto principal para prolongarse unos $860 \mathrm{~m}$ en dirección sur y luego describir una pronunciada curva para tomar la dirección contraria y presumiblemente volver a encontrarse con el Campamento III cerca de su esquina sudeste, si bien el investigador alemán no halla evidencias de este último tramo, por lo que el trazado completo quedó por resolver. E1 investigador alemán lo interpretó como un anexo para tropas auxiliares del campamento de Nobilior (Schulten, I929: III-II6) (ver figura 5).

La muralla, en este caso, presentaba una anchura de $3 \mathrm{~m}$, siguiendo el modelo del Campamento III, con doble paramento de grandes bloques calizos y un relleno interior de piedra menuda y tierra. En algunos tramos Schulten encontró un tercer muro paralelo a los otros paramentos laterales a manera de espina central (I929: III). Se encontraron tres torres en la parte interna de la muralla con unas dimensiones de 3,2 × 3,5 m; 3,2 × 7,0 m y 2,7 × 3,8 m, separadas entre sí por 34 y $29,5 \mathrm{~m}$ respectivamente, lo que hizo sospechar a Schulten que podía existir un patrón de roo pies romanos, es decir, unos 29 m (I929: III). Se localizaron asimismo dos puertas consistentes en una simple interrupción del muro. La situada más al norte tenía $6,3 \mathrm{~m}$ de anchura y la sur, $4,5 \mathrm{~m}$, en este último caso defendida por $t i-$ tulus de 9,5 × 4,40 m (I929: III).
En cuanto a la distribución interna, las excavaciones descubrieron varios edificios en la parte norte del recinto, sugiriendo que el resto del Anexo no había sido construido, si bien también se apunta que los trabajos agrícolas podrían haber destruido la mayor parte de los restos. Schulten identificó I4 bloques constructivos, considerando los edificios pareados muy próximos entre sí como barracones que se dan la espalda, mientras que los edificios impares eran pequeños cuarteles triples (I929: II3-II4). Las medidas de los barracones este-oeste serán $45 \mathrm{~m}$ de longitud, mientras los norte-sur tienen al menos $60 \mathrm{~m}$, equivalentes a Ir y i8 contubernia respectivamente.

Como vemos, este «Anexo» presenta dos problemas fundamentales. Por una parte, su trazado; por otra, su interpretación y datación.

Por lo que se refiere a la primera de estas cuestiones, como hemos señalado, Schulten no completa su planta, dejando abierto su recorrido en la zona más meridional, coincidente con el cerro denominado $\mathrm{La}$ Mesta. Los trabajos de prospección de M. Luik y sus colaboradores en el año I997 en la Gran Atalaya de Renieblas documentaron nuevos hallazgos en el sector meridional de la muralla del Anexo del Campamento III, en concreto un tramo de muro de unos roo $m$ que continuaba el ya establecido por Lammerer en 1912 en dirección norte, rodeando toda la colina (Breuer, Luik y Müller, I999: I44).

Luik también descubrió un muro ligeramente arqueado de $\mathrm{I} 20 \mathrm{~m}$ de longitud y I $\mathrm{m}$ de altura que descendía por la pronunciada ladera de La Mesta partiendo del límite del Anexo, con dirección noroeste hacia el cerro Cotillo (Breuer, Luik y Müller, I999: I44, fig. 7), que considera romano (Luik, 2002b: 772); y también restos de otro muro de $2 \mathrm{~m}$ de anchura rodeando la cima de este último cerro, cuya construcción, en este caso, es puesta en relación con la Edad del Hierro más reciente (Luik, 2002b: 772). Dobson considera estos restos como muy inciertos (2008: 189).

No obstante, tal y como comenta Dobson, ni Schulten entonces ni los trabajos de Luik y su equipo después permitían reconstruir ni cómo ni dónde esta muralla enlazaba con el Campamento III. Supone después Dobson que el muro seguiría aproximadamente la curva de nivel de los IIoo $\mathrm{m}$, un poco más elevada que la de Renieblas III, para intestar con la 


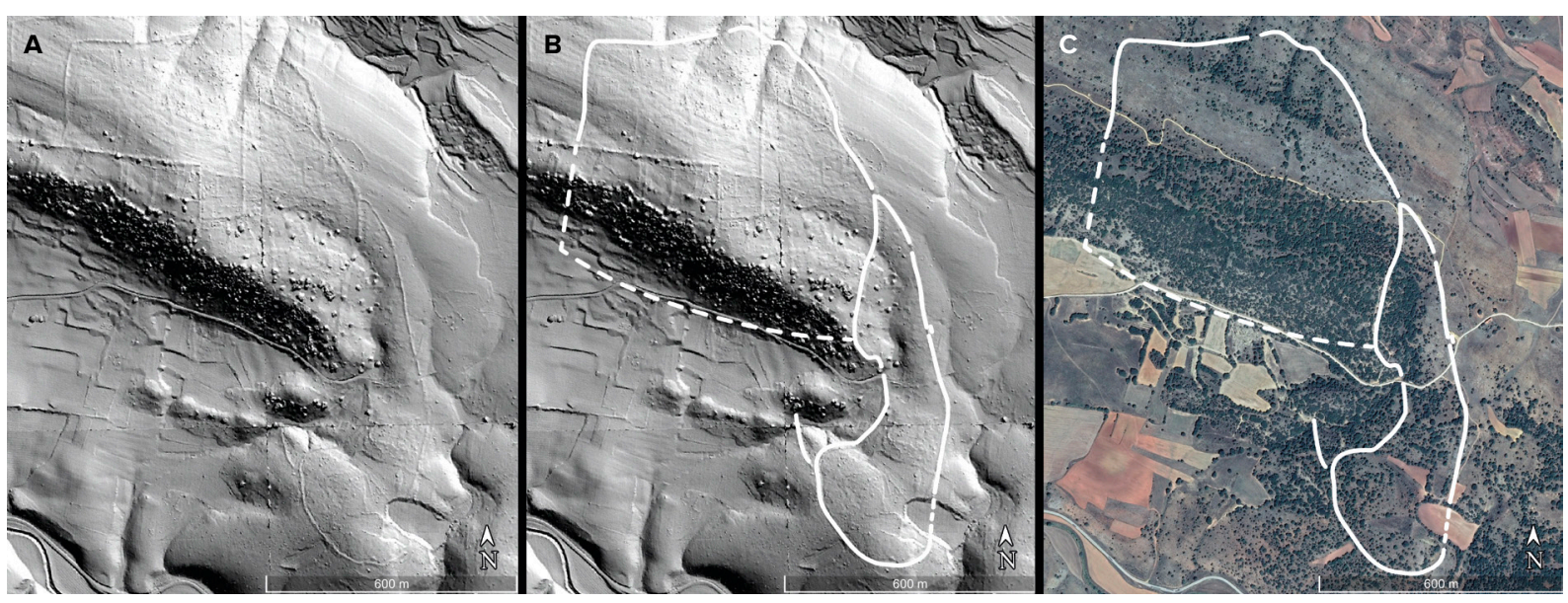

Figura 6. A. Imagen LiDAR del sector oriental del complejo militar de Renieblas, en el que se aprecia el Campamento III y su Anexo; B. Imagen LiDAR con recreación de las murallas del Campamento III y su Anexo; C. Planimetría de Campamentos III de Renieblas y su anexo a partir de LiDAR geoposicionada sobre imagen de google earth (C. Pereira)

Figure 6. A. LiDAR image of the eastern sector of the Renieblas military complex, in which Camp III and its Annex can be seen; B. LiDAR image with recreation of defences of Camp III and its Annex; C. Renieblas Camps III Planimetry and its annex from LiDAR geopositioned on google earth image (C. Pereira)

esquina sureste de este recinto, donde, a través de los diarios de Schulten, detecta ciertos restos constructivos (2008: 189, fig. 83).

Un estudio del terreno a través de los datos de LiDAR (Light Detecting and Ranging), también conocido como ALS (Airborne Laser Scanner), sensor remoto activo aerotransportado, nos ha permitido a los firmantes de este trabajo proponer una solución a la cuestión del trazado del «Anexo». La metodología empleada en este estudio es la usual en los datos PNOA. Obtenidos los archivos LiDAR (laz), estos fueron procesados de forma a construir un MDT (Modelo Digital de Terreno) de alta resolución que revela con nitidez las anomalías, las mas mínimas variaciones del suelo y micro-diferencias en las cuotas del terreno, mediante herramientas de visualización del relieve (Opitz y Cowley, 20I3; Hesse, 20Io). Este documento permite interpretar los relieves antrópicos, aplicándosele técnicas de visualización alternativas (sombreados, color, nitidez) (Štular et alii, 20I2), filtrando la capa superficial de vegetación, además de sobreponerse a otros documentos (cartográficos, fotográficos) con el objetivo de corroborar o aclarar determinadas lecturas de las anomalías (Forlin, 20I2; Kovacs et alii, 20I2). Este método se combina habitualmente con el estudio de la fotografía aérea, clásico sistema de teledetección de restos antiguos, construidos o excavados (Wilson, 1982; Picarreta, 1987).
El desarrollo de esa tecnología de teledetección y el avance de los medios de análisis formal del territorio de la última década ha repercutido además muy positivamente en la documentación de las estructuras campamentales antiguas, que requieren una necesaria comprobación sobre el terreno (vid., por ejemplo, Sánchez-Palencia y Currás, 20I5; Cordero et alii, 20I7; Costa y Fonte 20I7). Estos métodos se han convertido en una herramienta fundamental para conocer el proceso de conquista de Hispania por parte del ejército romano, en particular en el caso de estructuras constructivas de carácter efímero realizadas con materiales perecederos, como campamentos de marcha o campaña, que apenas dejan restos (Morillo et alii, 2020).

En efecto, en el caso concreto que nos ocupa, la tecnología LiDAR permite seguir en la topografía la línea defensiva del Anexo en su sector suroeste hasta completar su trazado, ya que las herramientas de visualización del relieve muestran indicios de la misma, que van desde anomalías muy claras, en el sector sur, a tenues indicios en el sector donde en Anexo engarza de nuevo con la esquina sudeste del Recinto III.

Así, continuando la línea de muralla establecida por Lammerer, ingeniero topógrafo de Schulten, y la sugerida por Luik que continuaba unos Ioo $\mathrm{m}$ la anterior, perfectamente confirmada ahora, continuaría 


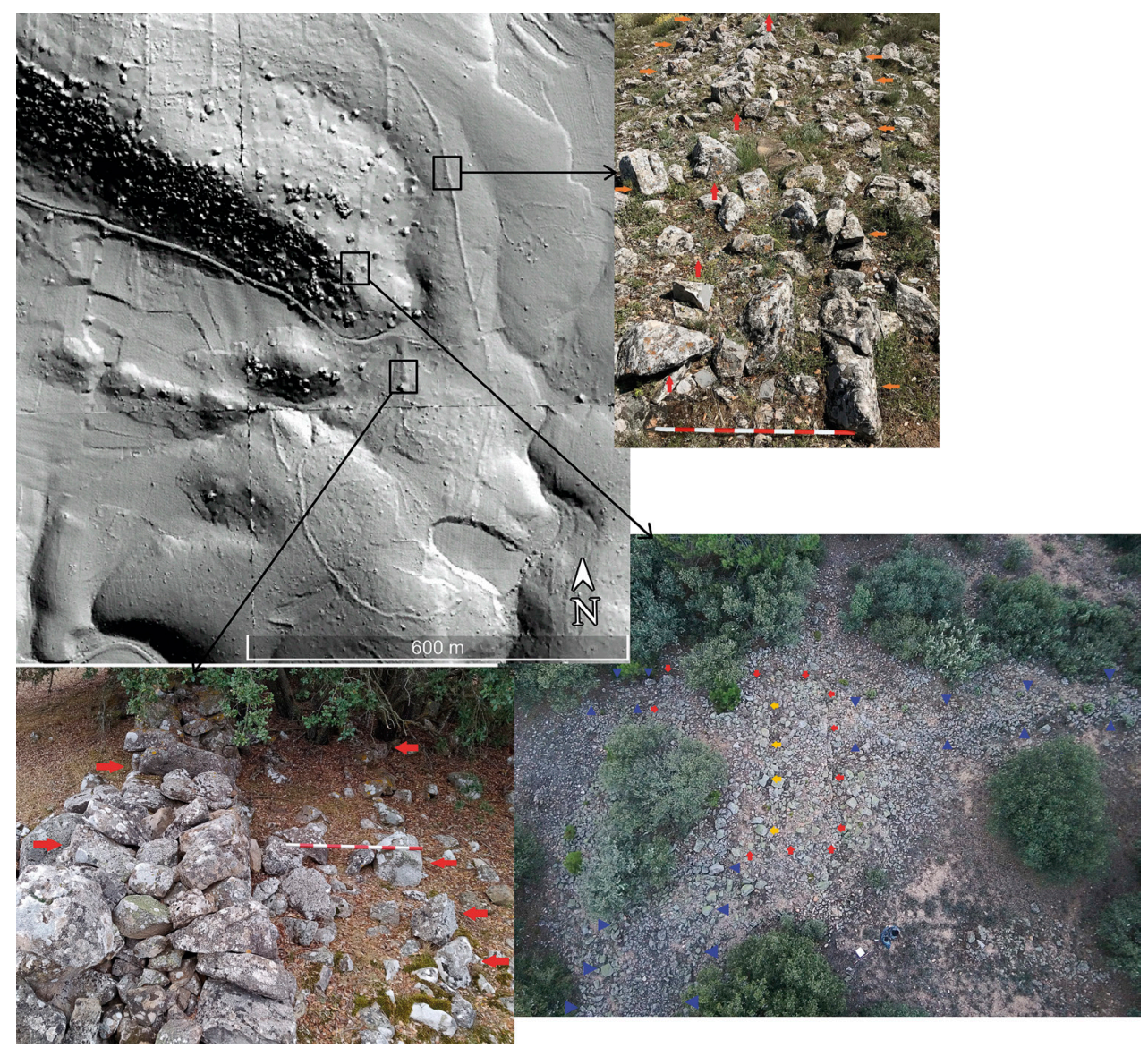

Figura 7. Evidencias arqueológicas de la muralla del Anexo del Campamento III de Renieblas (septiembre de 2020). Sector septentrional (F. Morales y https://www.arqueodrongia.net/com/ Renieblas/3379005, 15/09/2019)

Figure 7. Archaeological evidences of the walls of the Annexe of Camp III of Renieblas (september 2020). North area (F. Morales and https://www.arqueodrongia.net/com/Renieblas/3379005, 15/09/2019)

hacia el norte hasta cruzar por donde se encuentra la actual carretera secundaria, siempre siguiendo la curva de nivel de Iroo m. Posteriormente giraba hacia al oeste, formando un breve arco adaptando a la topografía para tomar de nuevo la dirección norte a través de un nuevo tramo recto hasta llegar a la esquina sureste del Campamento III, con la que intestaría por su lado meridional.

La superficie así resultante sería completamente irregular, de unas 14,5 ha, definida por un perímetro de unos $2070 \mathrm{~m}$. El eje mayor norte-sur seria unos $858 \mathrm{~m}$, mientras los ejes menores máximos (este-oeste) estarían en unos $270 \mathrm{~m}$ en su zona meridional y unos $195 \mathrm{~m}$, en la septentrional.

La reinterpretación de todo este sector a partir de la tecnología LiDAR que aquí presentamos (figura 6) permite asimismo confirmar la existencia de otro tramo de muralla descendiendo por las laderas de la colina de La Mesta en dirección, tal y como proponía el equipo de Luik (Breuer, Luik y Müller, I999: I44, fig. 7). En análisis mediante teledetección permite prolongar dicho tramo, que bajaba por la ladera de la colina con dirección noroeste-norte, hasta el mismo borde de la vaguada que le separa del vecino cerro Cotillo. La propia topografía nos indica que dicho tramo de muralla protege precisamente uno de los accesos naturales al «Anexo», donde deberían encontrarse una puerta (posiblemente coincidiendo con la posición de la carretera actual), configurando un espacio abierto protegido en la ladera de la colina La Mesta, tal vez un encerradero. En el engarce entre este tramo de muralla y el recinto defensivo del Anexo parece abrirse una entrada.

Evidentemente esta hipótesis de reconstrucción quedaba pendiente de una comprobación directa sobre el terreno, que llevamos a cabo durante 


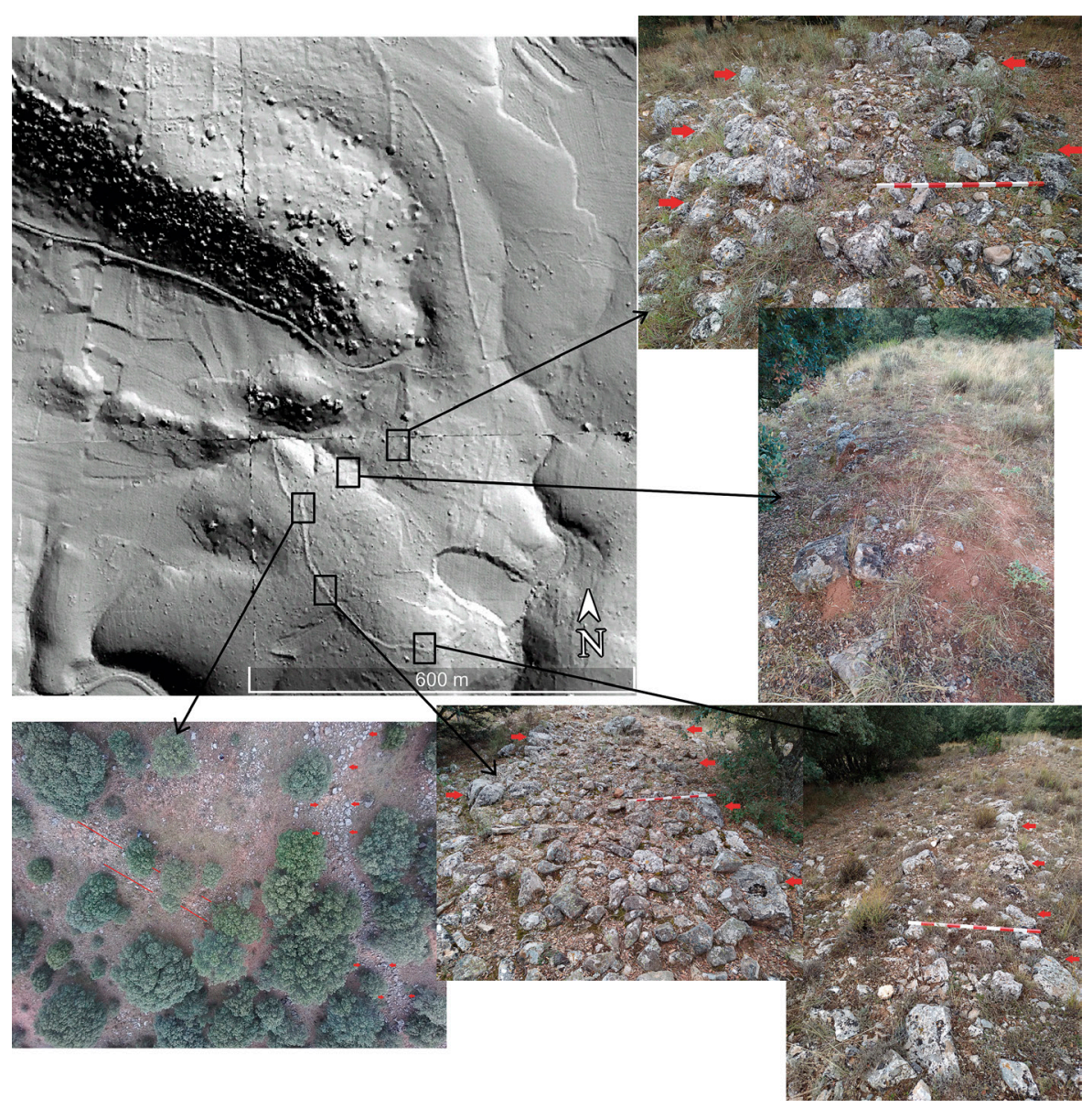

Figura 8. Evidencias arqueológicas del recorrido de la muralla del Anexo del Campamento III de Renieblas (septiembre de 2020). Sector meridional (F. Morales y https://www.arqueodrongia.net/ com/Renieblas/3379005, 15/09/2019)

Figure 8. Archaeological evidences of the walls of the Annexe of Camp III of Renieblas (september 2020). South area (F. Morales and https://www.arqueodrongia.net/com/ Renieblas/3379005, 15/09/2019)

los últimos meses y que ha permitido confirmar las evidencias detectadas a partir del LiDAR (figuras 7 y 8) Buena parte del lienzo oriental de este Anexo presentaba el sistema constructivo ya descrito por Schulten ( $3 \mathrm{~m}$ de anchura con muro interno paralelo a los paramentos laterales de grandes bloques calizos y relleno de piedra menuda) (Schulten, I929: III). Este lienzo se interrumpe al sureste por una gran terraza dedicada al cultivo de cereal para retomarse en dirección oeste rodeando el cerro de La Mesta. Aquí se ve un tramo de muralla ya conocido por Schulten, donde se aprecian los dos paramentos, manteniéndose el muro interior. En algunos sectores el paramento exterior ha desaparecido, con excepción de algunos bloques de piedra aislados, conservando únicamente el paramento interno y el muro interior, separados por unos I,5 $\mathrm{m}$.
A continuación, la muralla gira hacia el norte adaptándose a las curvas de nivel, donde se aprecian con claridad los paramentos que siguen definiendo los $3 \mathrm{~m}$ de anchura de la muralla, aunque en algunas zonas los derrumbes ocultan una o las dos caras del muro. Resulta visible puntualmente el muro interior paralelo a los paramentos. Justo antes de que la defensa gire hacia el noreste, se ve otro lienzo de mura1la que, definiendo un paso de unos 5-6 $\mathrm{m}$, se dirige a la muralla del Anexo que venimos describiendo, pero sin intestar con ella. Este segundo muro, baja por la ladera hasta la base del cerro Cotillo, que ya fue considerado por Luik como romano (Luik, 2002b: 772).

En el siguiente sector que gira hacia el noreste para luego tomar la dirección norte fue donde Schulten perdió la pista de la muralla. Sin embargo, el rastreo sobre el terreno a partir de la imagen 
LiDAR ha permitido continuar su trazado. El paramento interior ha desaparecido casi por completo en los primeros metros, derrumbada en el ribazo, mientras la cara exterior de la muralla se conserva in situ. Un poco más adelante, justo cuando comienza a girar en dirección norte, la muralla es de nuevo perfectamente reconocible, con sus dos paramentos y el muro interior paralelo, manteniendo los aproximadamente 3 metros de anchura total. Pocos metros antes de llegar al camino que corta la fortificación, se sigue viendo la muralla, si bien el paramento exterior y parte del relleno quedan camuflados bajo muros modernos. Sin embargo, todavía se aprecian por debajo el paramento interior y el muro interno, con el relleno de piedras menudas.

A partir del cruce con la carretera, se pierde cualquier indicio de la muralla en la prospección sobre el terreno. En este pequeño sector, hasta la esquina sureste del Campamento III, debemos contar únicamente con la ayuda del LiDAR para segur el trazado. Este sector de la esquina del Campamento III presenta numerosos restos de piedra suelta perteneciente tanto a la propia torre como a los lienzos que intestan con ella desde el norte y el oeste. La excavación de Schulten y el abandono sufrido por el yacimiento ha propiciado el derrumbe de todo el relleno interior, que ha ocultado en ocasiones los bloques de los paramentos exteriores y del muro interior paralelo. Aun así, pueden apreciarse los límites de las unidades estructurales. Muy llamativa es la presencia de un paramento interno de la torre que discurre casi en línea con la cara interna del lienzo oriental de la muralla, lo que parece constituir un indicio constructivo de la propia torre, recrecida en dirección oeste a partir del lienzo norte. El lienzo oeste de la muralla parece presentar una anchura menor (aproximadamente $2 \mathrm{~m}$ ) que anchura estándar del Campamento III y que los $3 \mathrm{~m}$ del lienzo oriental del Anexo, aunque los derrumbes no permiten reconocer con claridad los paramentos. Por otro lado, algunos indicios, al este de la torre, podrían apuntar al arranque de la muralla del Anexo que venimos describiendo.

Otra cuestión abierta es la cronología e interpretación de este "Anexo». Recientemente un detallado estudio de Dobson considera que la conclusión de Schulten, que lo considera un añadido para auxiliares es posible, pero que puede ser más válido el atribuir los restos de este supuesto anexo a una fase cronológica diferente a la del Campamento III, posterior desde el punto de vista cronológico. Y propone su denominación como Campamento VI (2008: 188). Este autor fundamenta dicha hipótesis en las diferencias constructivas respecto a Renieblas III tanto en lo relativo al sistema defensivo como respecto a las construcciones interiores (2008: 190-I9I).

Por lo que se refiere a la fisonomía del sistema defensivo, Dobson apunta como uno de los principales argumentos la diferente naturaleza de las entradas de ambos recintos. Como ya hemos visto, si las de Renieblas III presentan torres rectangulares de flanqueo, las del anexo están protegidas mediante un titulus.

Sin embargo, otros aspectos como el sistema constructivo empleado para la muralla muestras mayores similitudes con las de Renieblas III. Dicha estructura, si bien presentaba un menor espesor ( $3 \mathrm{~m}$ frente a 4-5 $\mathrm{m}$ del Campamento III) se había construido mediante la misma técnica de doble paramento de grandes bloques calcáreos y relleno interior piedra menor y tierra, sin cimentación. También en el caso del recinto defensivo del Anexo Schulten documentó la existencia de un tercer muro paralelo a los dos paramentos laterales a manera de espina central (1929: III) (figura 9a y 9b). Dobson cuestiona la existencia de este muro interior en la muralla del Anexo y lo atribuye a una «reconstrucción excesivamente entusiasta del alemán» (2008: 189). Sin embargo, es precisamente esta forma de construcción un argumento de diferenciación cronológica respecto a la datación asignada tradicionalmente a Renieblas III, ya que solo se verifica algo semejante en tramos de la cirvumvallatio situados cerca de Peña Redonda y Dehesilla (Schulten, I929: 5I). Por otra parte, este tercer paramento interior todavía puede apreciarse sobre el terreno (figura ro).

Otro aspecto más en que se parecen tanto el recinto principal de Renieblas III como su Anexo es en el intervalo de separación entre las torres, en los que se detecta un patrón semejante a Ioo pies romanos (29 m).

Sin duda las mayores diferencias entre ambos recintos hacen referencia a las estructuras interiores. El carácter de los barracones pareados espalda con 


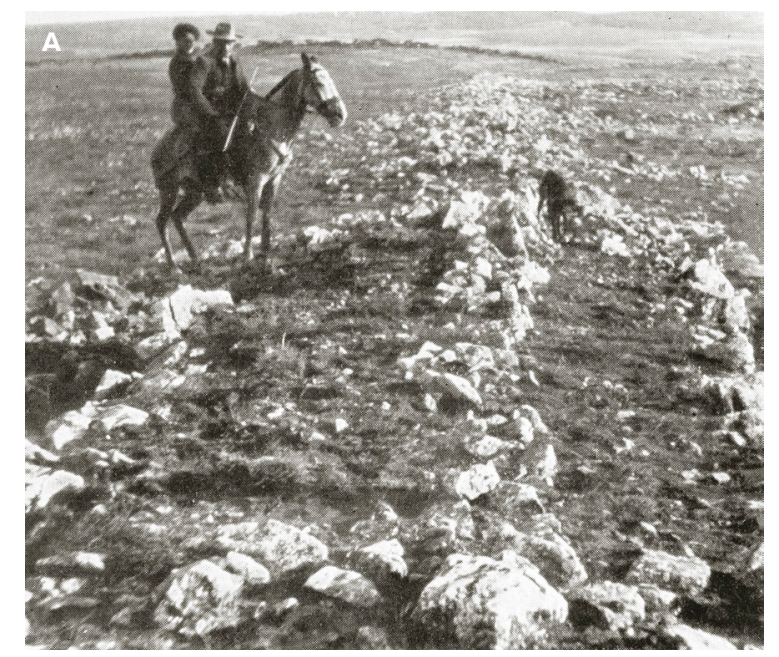

B

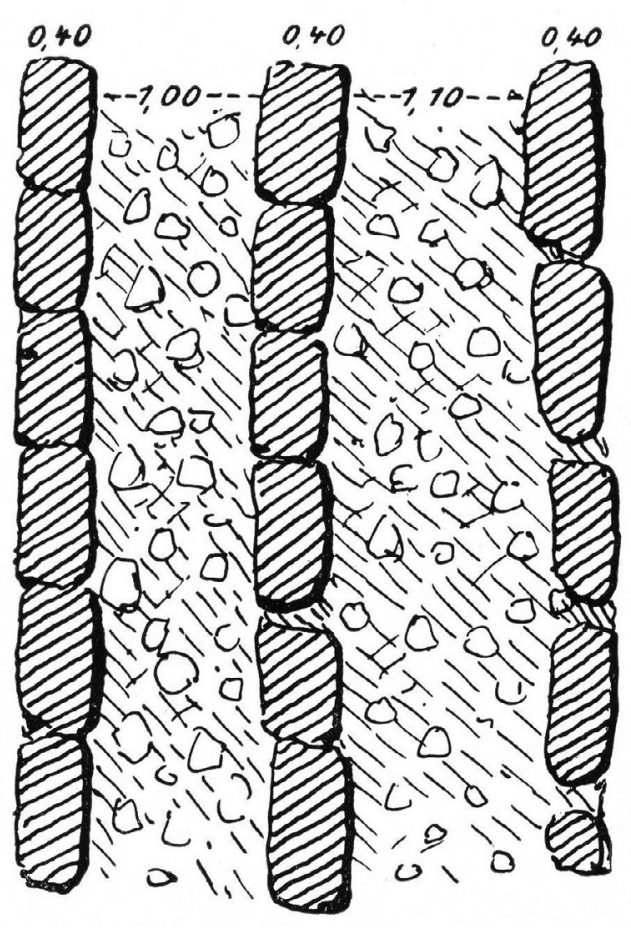

Figura 9. A y B. Fotografía y dibujo de Schulten de la muralla del Anexo del Campamento III de Renieblas (Schulten, 1929: lám. VII)

Figure 9. A y B. Photograph and drawing by Schulten of the wall of the Annexe of Camp III of Renieblas (Schulten, 1929: Plate VII)

espalda del anexo es muy diferente a los bloques más espaciados dobles y triples del Campamento III. La distribución del campamento parece haber consistido en una alineación de al menos catorce cuarteles dobles a lo largo de la muralla. Esta disposición es comparable con las filas de bloques de barracones del mismo tipo del campamento escipiónico de Peña Redonda, lo que apoya una concepción diferente, y por lo tanto una cronología posterior a la propuesta por Schulten para Renieblas III (Dobson, 2008: 19I-193).

Comenta Dobson que, con los datos disponibles, no es posible aventurar el tipo o tamaño de la unidad que ocupó el campamento, aunque la forma de los barracones parece indicar que fue infantería y no caballería. Para este autor, si la similitud entre estos cuarteles y los de Peña Redonda es válida, significaría que el «Campamento VI» también fue ocupado por tropas organizadas en cohortes, y que la idea de Schulten de que el «Campamento VI» era un anexo del Campamento III, de estructura claramente manipular no resulta válida. E1 supuesto «Anexo» sería un campamento nuevo fundado por Escipión como ampliación del reocupado «Campamento escipiónico III» (Dobson, 2008: I9I-I93).

\section{La evidencia arqueológica: Ios materiales del Campamento III a debate}

Si ya de por sí la aparición o ausencia de ciertos materiales arqueológicos en un contexto u otro está sometido a numerosas variables derivadas de las propias circunstancias de formación del registro arqueológico (contexto primario o secundario, condiciones de la amortización, intrusiones, etc.), la aplicación de una u otra metodología de intervención puede alterar o falsear completamente nuestras apreciaciones de carácter cronológico y funcional (Morillo y Adroher, 20I4b: 3I-33). El caso de los campamentos romanos republicanos de Renieblas es uno de los que mejor ejemplifica la dificultad de obtener dataciones cronoestratigráficas ajustadas cuando no se aplica la metodología correctamente, a pesar de ser uno de los yacimientos para los que poseemos una documentación más abundante, tanto literaria como arqueológica, que avalan su carácter multifásico. No podemos olvidar que Schulten recogió los materiales de las diferentes fases superpuestas en conjunto, sin considerar sus relaciones estratigráficas verticales u horizontales, por lo que las asociaciones plantean problemas de interpretación más que graves. A pesar de sus escasos conocimientos estratigráficos, 


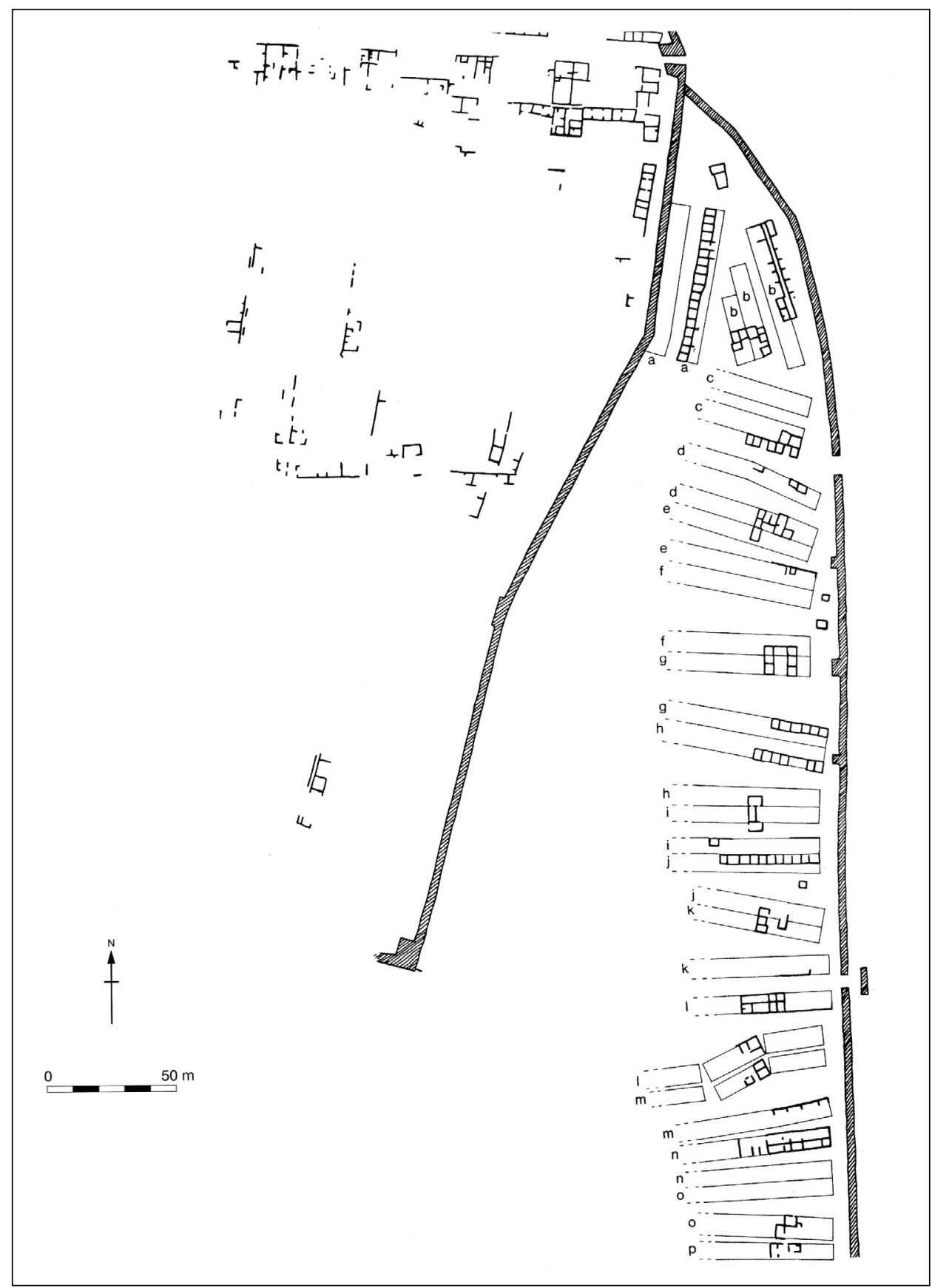

Figura 10. Reinterpretación del Anexo del Campamento III por parte de Dobson, que lo denomina «Campamento Vl» (Dobson, 2008: 188-193)

Figure 10. Dobson's reinterpretation of Camp III Annex who calls it "Lager VI” (Dobson, 2008: 188-193)

el investigador alemán defendía su forma de trabajar porque los hallazgos se producían cerca de las paredes, y sobre todo en las esquinas de las habitaciones. Sin embargo, la información que se perdió entonces resulta imposible de recuperar, ya que fueron pocos los interiores que se excavaron completamente y por tanto sus resultados fueron muy limitados (Dobson, 2008: 28). Habría que tener en cuenta el lugar exacto del hallazgo para establecer si estamos ante un hallazgo coetáneo al momento de campamento en el que se hallaron o si estamos ante una zona con otros campamentos infrapuestos o superpuestos, de los que podría asimismo proceder la pieza en concreto (Morillo y Morales, 2015: 295). Pero a pesar de la buena calidad de planimetrías, dibujos y secciones, no siempre contamos con dicha 
información, lo que impide obtener una secuencia estratigráfica concluyente.

Los campamentos de la circumvallatio de Numancia y Renieblas siguen siendo un punto de referencia constantemente utilizado en los estudios de los materiales de importación a mediados del siglo in a. C. Sin embargo, continúa existiendo un problema por el momento irresoluble en lo referente a unos materiales cuyo contexto adecuado sigue sin estar claro, y de ahí la pertinente pregunta del propio Principal: ¿existe una facies de los campamentos numantinos? (2013: 348).

Siguiendo al autor anterior, en cuanto a los productos anfóricos, tenemos una tríada perfectamente organizada, con productos vinarios con grecoitálicas y Dressel I (a los que habría que unir los morteros de las misma procedencia itálica, lo que sucede constantemente en el Mediterráneo antes del cambio de era, ya que los morteros se utilizan en procesos de consumo de vino, de modo que ánforas y morteros tienen siempre la misma procedencia); las T-9.I.I.I, conocidas tradicionalmente como Campamentos Numantinos (CCNN), parecen indicarnos el consumo de productos de pescado procedentes de la bahía de Cádiz o Málaga; y para terminar, las ánforas tripolitanas nos hablarían del aceite de procedencia norteafricana (Sanmartí, I985).

Desde el punto de vista de la cerámica de mesa, asistimos a la constante presencia de barniz negro universal, que sustituye con el paso del tiempo a los productos campanos por los etruscos y los calenos, acompañada por cubiletes de paredes finas, lucernas Ricci E y F (Romero, 1990), o los ungüentarios fusiformes, todo ello de importación itálica. Este panorama dibuja un modelo de abastecimiento militar propio del siglo iı a. C. (Sanmartí y Principal, r998; Principal, 2000, 2013).

En relación con los campamentos numantinos, se han propuesto incluso ciertas concomitancias entre terminología grecolatina y tipología cerámica documentada a partir de los textos de Plutarco, Apiano y Polieno, quienes mencionan los utensilios que portarían las tropas a título personal tras la reforma realizada a la llegada de Escipión a su destino en Numancia (Santapau, Herreros y Sanfeliu, 2003); así, los cubiletes de paredes finas y las copas de barniz negro servirían para la bebida, las chytrai y caccabai para la cocción de gachas, y habría que plantearse que los platos de barniz negro se utilizarían bien para el consumo de las gachas y/o de carnes cocidas, cuando no de copas para beber propiamente dichas (Morais, Morillo y Adroher, 2016: 718).

A pesar de los inestimables intentos de revisión de los problemas contextuales relativos principalmente a la cerámica de barniz negro por parte de autores como Sanmartí y Principal, da la impresión de que se ha creado un argumento circular que asocia un conjunto de determinadas formas y producciones a los campamentos escipiónicos, formas y producciones que precisamente por estar en dichos recintos pasan a ser el patrón material característico del tercer cuarto del siglo II a. C. (I50-I25 a. C.) a nivel de bibliografía global puesto que están en contextos de la guerra numantina. Todo ello sin considerar que algunos campamentos como Renieblas pueden arrojar fechas varias décadas anteriores o posteriores para los mismos materiales. No cabe duda de que las dataciones absolutas derivadas de la carencia de estratigrafías bien caracterizadas nos hayan llevado a atribuciones discutibles que pueden incluso haber sesgado de alguna manera la cronología que manejamos en la bibliografía para materiales como la cerámica de barniz negro. Cada vez resulta más evidente, salvo que estemos ante yacimientos claramente monofásicos, que es muy arriesgado emplear materiales carentes de una estratigrafía clara para establecer dataciones ajustadas. Todo lo más movernos en una amplia horquilla cronológica de referencia.

En el caso que nos ocupa, cada vez son mayores las contradicciones desde el punto de vista del registro material, que se deja notar en la investigación sobre ceramología republicana, en demostración de la ineficacia del método de datación. Uno de los ejemplos más claros los ofrece la numismática, materiales curiosamente menos estudiados, a pesar de sus posibilidades de datación incluso mayores que los recipientes de mesa para este periodo tardorrepublicano. Así, por ejemplo, el propio Schulten apuntó el hallazgo en el recinto del Campamento III de Renieblas de un denario acuñado por Sex. Pom(peius) Fostlus, datado en el I37 a. C. (1929: 263; Crawford, 1974: 267-268 n. 235). Aunque no está claro quién fue ese personaje y, por lo tanto, las circunstancias históricas de la 

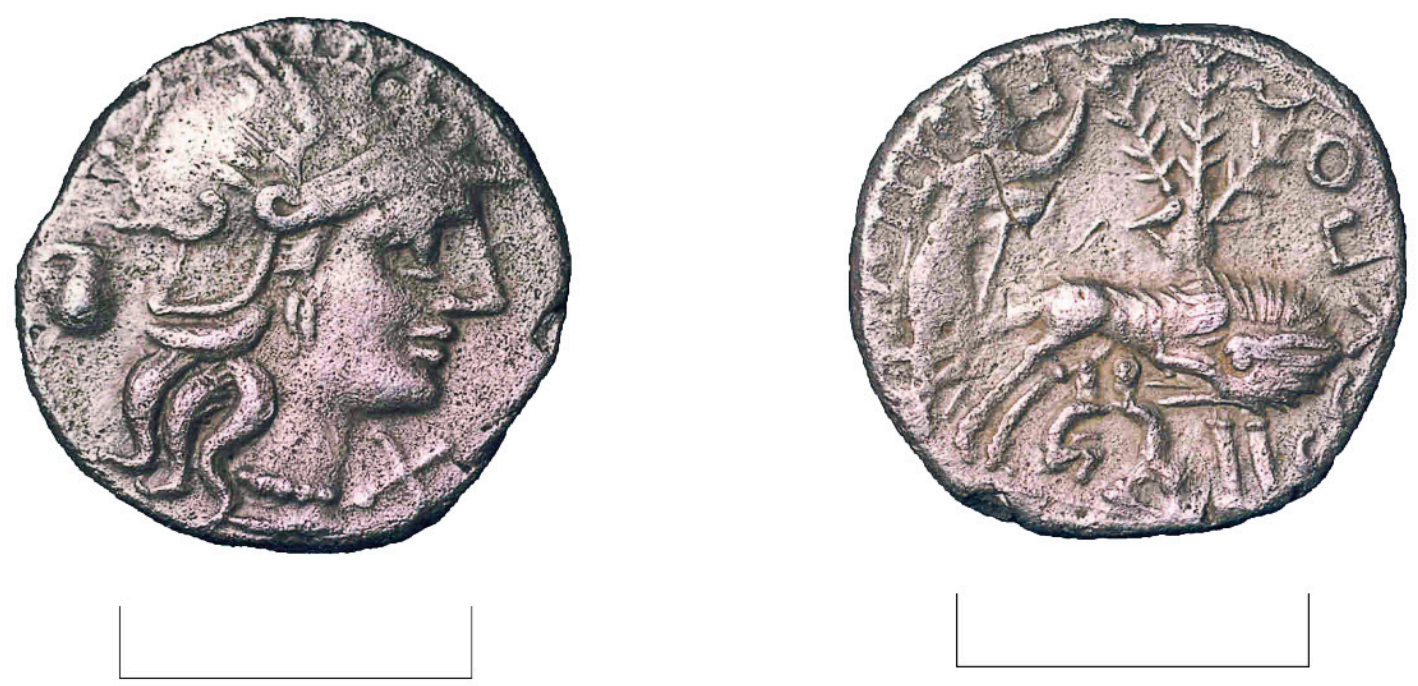

Figura 11. Anverso y reverso del denario de Sex. Pompeius Fostlus hallado en Castillejo. (Dobson y Morales 2008: fig. 1.1) Figure 11. Denarius of Sex. Pompeius Fostlus (Dobson and Morales, 2008: fig. 1.1)

emisión de la moneda, la fecha difícilmente es congruente con la que el propio Schulten atribuye a la ocupación del campamento donde se encontró, que es el año I53-152 a. C. No cabe duda que llegó allí posteriormente, más que en época de Mancino en el mismo año de la acuñación (I37 a. C.) (Ap. Iber. 80), coincidencia de fechas que descarta casi totalmente esta posibilidad, en el bolsillo de las tropas de Escipión.

Curiosamente, se ha dado a conocer hace pocos años, dentro de un conjunto de monedas de los campamentos republicanos del cerco de Escipión y la Gran Atalaya de Renieblas, un denario idéntico procedente del recinto del Castillejo, que permite asociar el hallazgo de Renieblas III a los trabajos de la circunvalación para la toma de Numancia por Escipión (Dobson y Morales, 2008: 215; 2010: 326) (figura II).

Un argumento de mucha mayor consistencia ha sido el reestudio de los hallazgos numismáticos de los Campamentos III y V de Renieblas y los recintos de la circumvallatio numismática (Pamment Salvatore, I996: 26), a la luz de la premisa fundamental del antes citado estudio de Hildebrandt (1979), a saber, el bien atestiguado fenómeno de la pérdida de peso que sufrió la moneda de bronce en Roma a lo largo de los siglos ir y i a. C. causada por las sucesivas devaluaciones. La metodología de Hildebrandt para determinar cuándo fueron empleadas las monedas y así poder fechar los campamentos, estaba basada en su peso relativo y conservación. Su premisa parte de que el peso medio de las monedas de bronce acuñadas en Roma es conocido por haberse rebajado gradualmente durante los siglos iı y i a. C. Su propuesta es que podría identificarse una media de pérdida de peso gradual en las monedas de bronce romanas, y que esta reducción se reflejaría en las acuñaciones encontradas en los campamentos. Según esto, la muestra de monedas de bronce con el peso medio más alto debía ser más temprana (Pamment Salvatore, 1996: 26). $\mathrm{Su}$ análisis pone de manifiesto que la estación con el peso medio más alto era el de Renieblas III seguido de los campamentos del cerco de Escipión y, finalmente, de Renieblas $\mathrm{V}$, con el peso medio más ligero.

Según esto, si pusiéramos en una tabla las monedas de bronce de los tres contextos ordenadas por pesos, teóricamente la columna con las monedas de Renieblas III, que es el más antiguo y por tanto sus monedas deberían ser más pesadas, ocuparían la zona alta de la tabla. A continuación, la columna con las monedas de los campamentos del cerco de Escipión, de 20 años después, teóricamente menos pesadas que las anteriores, ocuparían la zona intermedia de la tabla. Y, finalmente, la columna con las monedas del Campamento V; en este caso, siempre en teoría, como no sabemos la fecha concreta de este recinto, sería la situación del peso de las monedas en la tabla la que nos indicara una orientación cronológica relativa, es decir, si los pesos de las 
monedas de Renieblas V son paralelos a los del cerco de Numancia, su fecha sería similar; si por el contrario son más ligeros, en teoría, su cronología sería más tardía. Una vez elaborada la tabla con los pesos reales de los ases romanos hallados por Schulten en los tres contextos (Dobson y Morales, 2008: 217), vemos que efectivamente la propuesta teórica se cumple en gran medida (figura I2).

El Campamento V sitúa la mayor parte de los pesos de sus monedas por debajo de los pesos de las monedas de los campamentos de Escipión. La diferencia apreciable en los pesos medios de ambos conjuntos, 33,64 g para los campamentos de cerco y 25,I7 g para Renieblas $\mathrm{V}$, parece estar confirmando una cronología posterior, por lo que se podría concluir que el Campamento $V$ no es contemporáneo del cerco de Escipión como pretendía Hildebrandt, sino que su fecha debería retrasarse algunos años (Dobson y Morales, 2008: 217).

De igual manera, en la columna del Campamento III hay varias monedas más pesadas que la primera más pesada de los campamentos de Escipión $(42,98 \mathrm{~g})$ que, además, procede de Castillejo, y que por su peso destacado es susceptible de pertenecer a cualquiera de las dos fases preescipiónicas y no ser coetáneas del cerco. Las monedas más pesadas de Renieblas III están apuntando una mayor antigüedad para este recinto. Respecto a los pesos medios de los dos conjuntos, si tenemos en cuenta la premisa de que «la muestra con la media de peso más alta es más temprana», el Campamento III tiene un peso medio de $35,22 \mathrm{~g}$, frente a los 33,64 g del conjunto escipiónico, una diferencia muy poco significativa que no justifica los 20 años que separan ambos contextos. Resulta sospechoso que los hallazgos monetarios Renieblas III presenten pesos tan variados, entre los 55,29 g del ejemplar más pesado y los 22,55 $\mathrm{g}$ del más ligero, de forma que este rango engloba todos los pesos de las monedas de los campamentos numantinos, entre 42,98 g y 25,I2 $\mathrm{g}$. Es decir, que Renieblas III está en la misma ratio que los campamentos escipiónicos, lo que no tiene justificación dada la corta estancia de Nobilior y plantea una contradicción insoslayable.

Aun teniendo en cuenta que los campamentos del Talayón de Renieblas se superponen unos a otros, que ha podido haber arrastres de materiales de una zona a otra y que el modo en que Schulten registró los hallazgos demuestra su escaso aprecio por las consideraciones estratigráficas y por la precisa topografía, lo que puede haber mezclado materiales de varios recintos (Luik, 2002a: 175), Dobson y Morales sugieren que el análisis numismático indicaría que el Campamento III de Renieblas pudo haber soportado ocupaciones en fechas posteriores a la tradicionalmente asignada, es decir, que el campamento de Nobilior pudo haber sido reocupado por las tropas de Escipión con motivo del asedio de Numancia, y que las monedas aquí halladas con pesos equivalentes a las de los campamentos del cerco no hacen sino certificar su estancia en este lugar (2008).

Hace pocos años, Jiménez ha vuelto sobre la cuestión de los hallazgos numismáticos de Renieblas III, señalando que la elevada presencia de victoriatos de plata de finales del siglo in y comienzos del II, así como moneda de bronce contemporánea y su estado de conservación indicaría un patrón de circulación más antiguo, por lo que las monedas llegadas para pagar a las tropas alcanzarían este recinto durante las primeras décadas del siglo iI a. C. y no durante las guerras celtibéricas, aunque el hallazgo de monedas más modernas hablaría de ocupaciones a lo largo del siglo II e incluso posteriores (2014: 386). Aun así, indica que habría que buscar una explicación acerca de la llegada de moneda más antigua y en buen estado de conservación a recintos de las guerras celtibéricas, entre 40-70 años más tarde al momento de acuñación (20I4: 386).

Dejando al margen la indudable aportación de Jiménez derivada del análisis de los datos con una perspectiva mucho más moderna, de nuevo en esta ocasión queda de manifiesto el problema metodológico que plantea el tratar un yacimiento multifásico sin relaciones estratigráficas claras como si tuviera una única ocupación. Aunque se está hablando de Renieblas III no queda claro si las consideraciones de carácter cronológico se refieren solo a dicho recinto o al conjunto de todos los campamentos superpuestos, que fueron abandonados y reocupados por tropas diferentes en varias ocasiones por lo que no puede haber una circulación residual en el ámbito de un mismo recinto, como sucede en los acantonamientos altoimperiales del limes. Por lo tanto podríamos plantearnos varias preguntas: ¿la numismática indicaría que Renieblas III se 


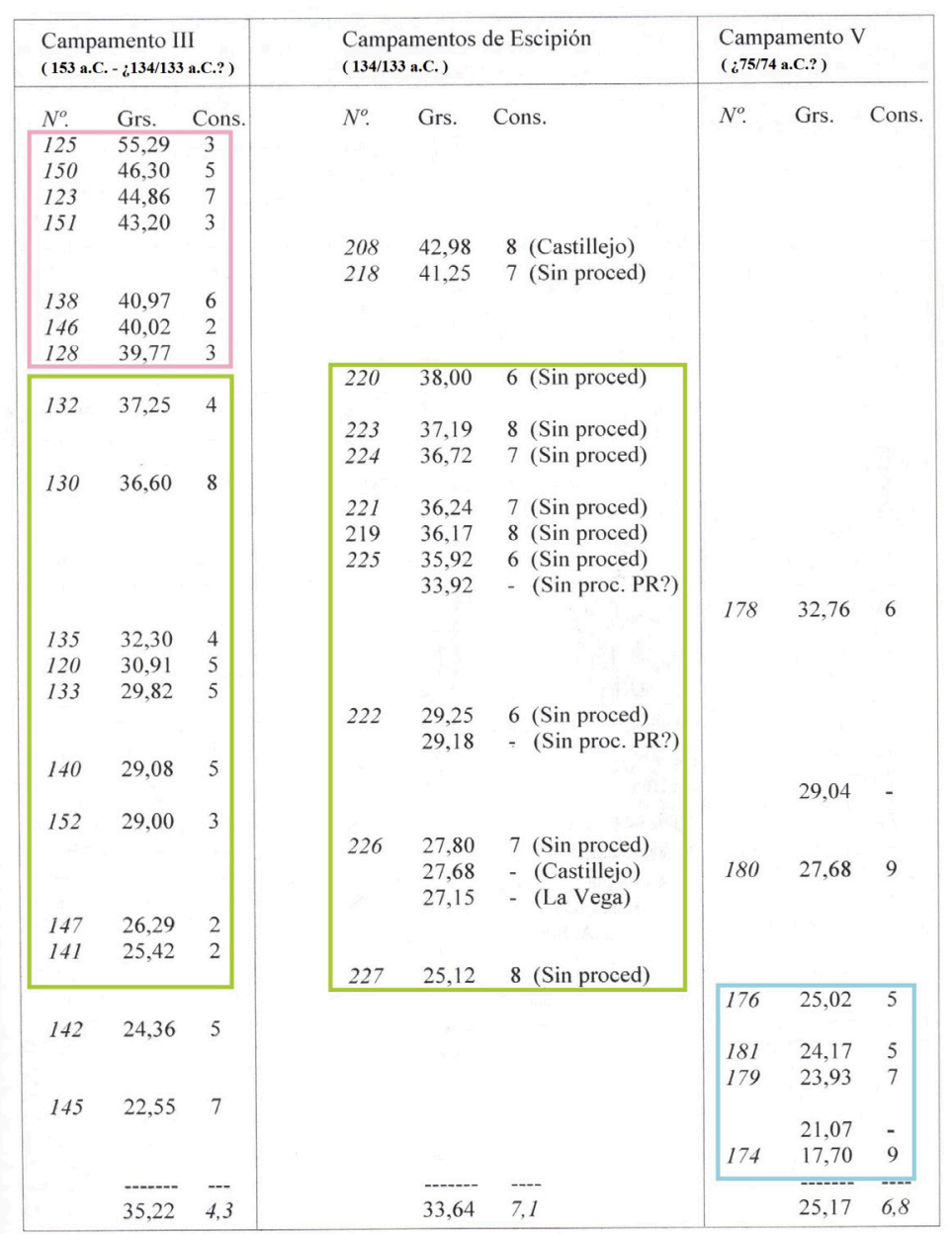

Figura 12. Tabla de los pesos de la moneda bronce hallada en el Campamento III de Renieblas, en los campamentos de la circumvallatio numantina y en el Campamento $\mathrm{V}$ de Renieblas ordenados de mayor a menor. Los recuadros verdes indicarían los pesos similares entre el Campamento III y los campamentos de la circumvallatio, indicio de ocupación coetanea. En rojo los pesos más altos presentes en el Campamento III. En azul los pesos más bajos presentes en el Campamento V de época sertoriana (Dobson y Morales, 2008: 218, fig. 3 con modificaciones)

Figure 12. Table of the bronze coins weights found in Camp III of Renieblas, the camps of the circumvallatio numantina and in Camp $V$ of Renieblas ordered from highest to lowest. The green squares would indicate the similar weights between Camp III and the camps of the circumvallatio, proof of contemporary occupation. In red the highest weights present in Camp III. In blue the lowest weights present in Camp V from the Sertorian period (Dobson and Morales, 2008: 218, fig. 3, with modifications)

fundó en las primeras décadas del siglo ir a. C., antes del r7o a. C. cuando al parecer deja de emitirse el victoriato? No parece defendible; ¿estamos hablando de moneda perdida anterior perteneciente a Renieblas I y II?; tampoco parece muy probable; ¿el patrón de circulación en este periodo tardorrepublicano en Hispania aparenta ser muy retardatario entre las tropa, posiblemente por la posible acuñación en suelo hispano de victoriatos precisamente para pagos al ejército? Esta hipótesis ya ha sido apuntada, en particular para las últimas series de victoriatos ( $\left.\mathrm{RRC}_{53} / \mathrm{r}, \mathrm{RRC} 67 / \mathrm{r}, \mathrm{RRC} \mathrm{r66} / \mathrm{I}\right)$, donde hay numerosas piezas con pesos más bajos (Marchetti, 1978: 386-399; García-Bellido, I986; Lechuga Galindo, 1986: 65-68). Esta posibilidad resolvería el problema de la datación temprana de los victoriatos de Renieblas III al tratarse de acuñaciones posteriores de imitación.

Otra de las evidencias que podrían ayudar a la clarificación cronológica son los abundantes restos de militaria, armas e indumentaria. Sin embargo, la 

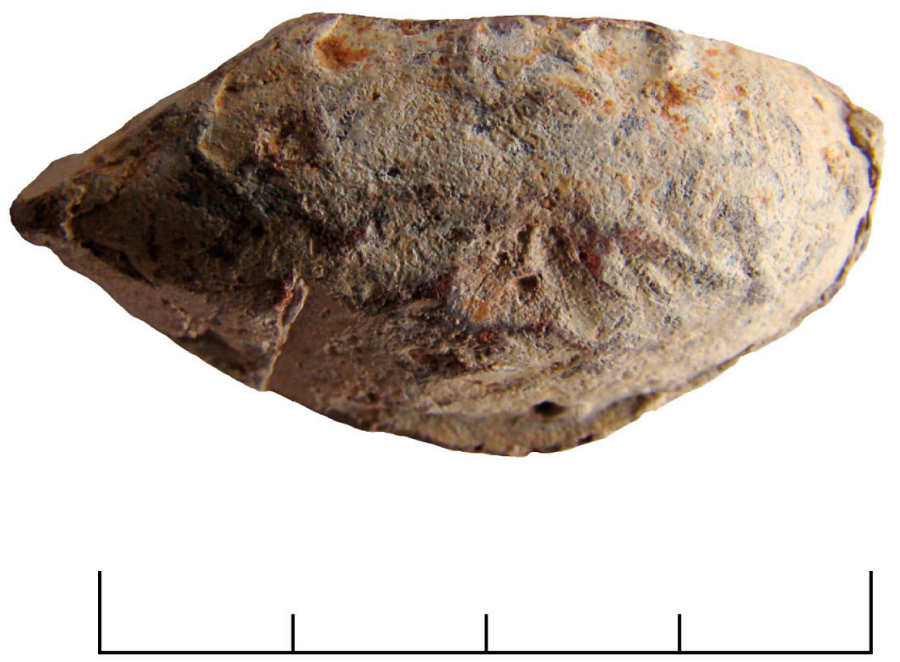

Figura 13. Glande de los etolios procedente de la Gran Atalaya de Renieblas (Gómez-Pantoja y Morales 2008: fig. 7)

Figure 13. Lead slinghot of Etolians found in La Gran Atalaya de Renieblas (Gómez Pantoja and Morales, 2008: fig. 7)

horquilla cronológica que marcan estos materiales es todavía muy amplia y no permite aquilatar un marco temporal más reducido. $Y$, al igual que sucede con la cerámica romana de barniz negro, la propia presencia de determinados materiales en los contextos de Numancia, ha llevado a considerarlos propios la época de las guerras celtibéricas en la bibliografía general sobre militaria romana, sin considerar que podrían ser elementos de larga perduración.

Tan solo algunos elementos aislados podrían dar alguna pista en este sentido. La presencia de tropas escipiónicas en Renieblas podría verse confirmada por el hallazgo de una bala honda de plomo en algún lugar indeterminado de Renieblas, que portaba una curiosa leyenda en caracteres griegos: Ai $\tau \omega \lambda \tilde{\omega} \nu$ (Gómez-Pantoja y Morales, 2008). Como hallazgo aislado y descontextualizado, la bala etolia podría pertenecer a cualquiera de los campamentos de La Gran Atalaya. No obstante, la tradición literaria vincula a Escipión con el uso de la honda, lo que sin duda implicaría a estos honderos etolios. Apiano también asegura que el contingente que acompañó a Yugurta a Numancia incluía honderos, que Escipión mezcló con sus tropas con la intención de aumentar su potencia de fuego (Gómez-Pantoja y Morales, 2008: 49). El hallazgo de otras cuatro glandes con esta misma leyenda procedentes, al parecer, de alguno de los campamentos del sur de la circunvallatio numantina (González, 1996) parece confirmar la presencia de honderos etolios en el asedio escipiónico y vincular el hallazgo de Renieblas con dicha presencia (Gómez-Pantoja y Morales, 2008: 49). Pero tampoco debe descartarse que contingentes con esta misma procedencia participaran en campañas anteriores (figura I3).

\section{Renieblas III: ¿campamento unifásico o bifásico?}

Tal y como hemos ido apuntando en varias ocasiones, Schulten no tiene ninguna duda de la datación del recinto III de Renieblas durante las campañas del I53 a. C del cónsul C. Fulvio Nobilior. Las referencias de la distancia del campamento del cónsul respecto a Numancia y su coincidencia con Renieblas, unido a la solidez constructiva de Renieblas III, que lo identifica claramente como castra hiberna, le llevaron a aceptar esta identificación. Los materiales arqueológicos propiamente dichos fueron un argumento de segundo orden para el investigador alemán. El marco cronológico de época sertoriana establecido para los recintos posteriores, Renieblas IV y V alejaban por completo la posibilidad de una ocupación escipiónica de La Gran Atalaya (I929: 4I y I37-I45). 
No obstante, sin negar en ningún momento la construcción de Renieblas III en época de Nobilior, ni la datación sertoriana de Renieblas IV y V, que se ve confirmada por recientes hallazgos (Luik, 2002a; Gómez-Pantoja y Morales, 2002; Morillo et alii, 2017: 194), tal y como hemos ido apuntando a lo largo de estas páginas siguen existiendo contradicciones y aspectos no resueltos en la secuencia de ocupación de este complejo yacimiento, que tal vez nunca puedan resolverse.

En primer lugar, las propias fuentes clásicas, concretamente Apiano, señala la existencia de un recinto militar de Escipión anterior a los campamentos de la circumvallatio y situado a mayor distancia que estos de Numancia, pero en sus proximidades, cuestión silenciada por Schulten. En ningún momento se indica su posición. Por nuestra parte, en los últimos años hemos abordado en diversos trabajos la cuestión del cerco numantino para plantear la necesaria revisión de presupuestos de Schulten, como la planta de los campamentos, su sistema constructivo y la datación del complejo de Renieblas (Morillo, 2008, 20I4; Morillo y Adroher, 20I4a y 20I4b; Morillo y Morales, 20I5; Morillo et alii, 2017: 189-I9o; Morales, 202I).

Apiano no vuelve a referirse a este campamento «primigenio», pues a partir de ahora centra su atención en el asedio y en Numancia. Sin embargo, es posible que este recinto siguiera funcionando y sirviera también de base logística durante los trabajos de levantamiento de la circunvalación y a lo largo de todo el tiempo que duró el sitio, pues una campaña militar de tal envergadura (Apiano habla de 60000 combatientes en Iber. 92) debía necesitar un campamento de retaguardia no demasiado alejado del teatro de operaciones. Los dos campamentos y siete fuertes del cerco nunca pudieron albergar la totalidad de las tropas y pertrechos necesarios para una campaña invernal de asedio perfectamente planificada por Escipión. Las excelentes condiciones que ofrecía Renieblas en este sentido ya habían sido explotadas por Roma anteriormente. Se encuentra cerca, pero a la distancia suficiente para prevenir un posible ataque y ejerce un amplio dominio visual respecto a la ciudad arévaca y la mayor parte de los recintos de la circumvallatio. Resulta difícil creer que Escipión hubiera pasado por alto las posibilidades de este asentamiento para establecer su campamento base.
Además, el propio Schulten señala las grandes semejanzas constructivas que existen entre Renieblas III y los recintos militares y el muro de la circumvallatio, tanto a nivel de arquitectura defensiva, como a organización interna, que se ajusta casi perfectamente a las normas polibianas. A lo que podemos añadir asimismo las semejanzas entre el registro material entre ambos conjuntos, aunque la carencia de estratigrafías no nos permitirá nunca establecer una secuencia comparativa entre patrones de circulación de monedas o cerámicas, limitándonos a consideraciones y repeticiones en el registro arqueológico material, como hemos expuesto en su lugar.

Ya hace algunos años venimos sugiriendo que el campamento-base de Escipión debió establecerse en Renieblas (Morales, 2000: 239), en particular con el Campamento III a partir de ciertos indicios circunstanciales (Gómez-Pantoja y Morales, 2008: 5I-52) o evidencias de tipo arquitectónico y estratégico (Morillo y Morales, 2015: 295; Morillo et alii, 2017: 189-19o). Aceptar esta hipótesis significaría que los castra biber$n a$ de Nobilior del I53-I52 a. C. fue más tarde reocupado como campamento-base por Escipión veinte años después, en el I34-I33 a. C., lo que implica que estaríamos ante un recinto militar bifásico.

La costumbre del ejército romano desde que tenemos noticia a través de las fuentes implica el derribo sistemático de las estructuras defensivas y construcciones internas de los campamentos y fuertes militares temporales o estables tras su abandono hasta dejarlas casi a ras de suelo. No cabe duda que Nobilior debió proceder de dicha manera ya que Apiano nos relata que en el 137 a. C. Mancino ocupa el descampado (ह̋ como campamento de Nobilior, esto es, un lugar desolado y desmantelado. En un estado parecido debió encontrarlo Escipión en el I34 a. C., quien valorando la inmejorable posición y el espacio amplio de que disponía para albergar sus tropas, pudo aprovechar selectivamente las ruinas anteriores y emplear la abundante piedra procedente de las antiguas estructuras desmanteladas para erigir su propio recinto, que reproduciría a grandes rasgos el precedente. En el único espacio donde se apreciaría claramente la obra escipiónica sería en el llamado Anexo (Campamento VI para Dobson), erigido 


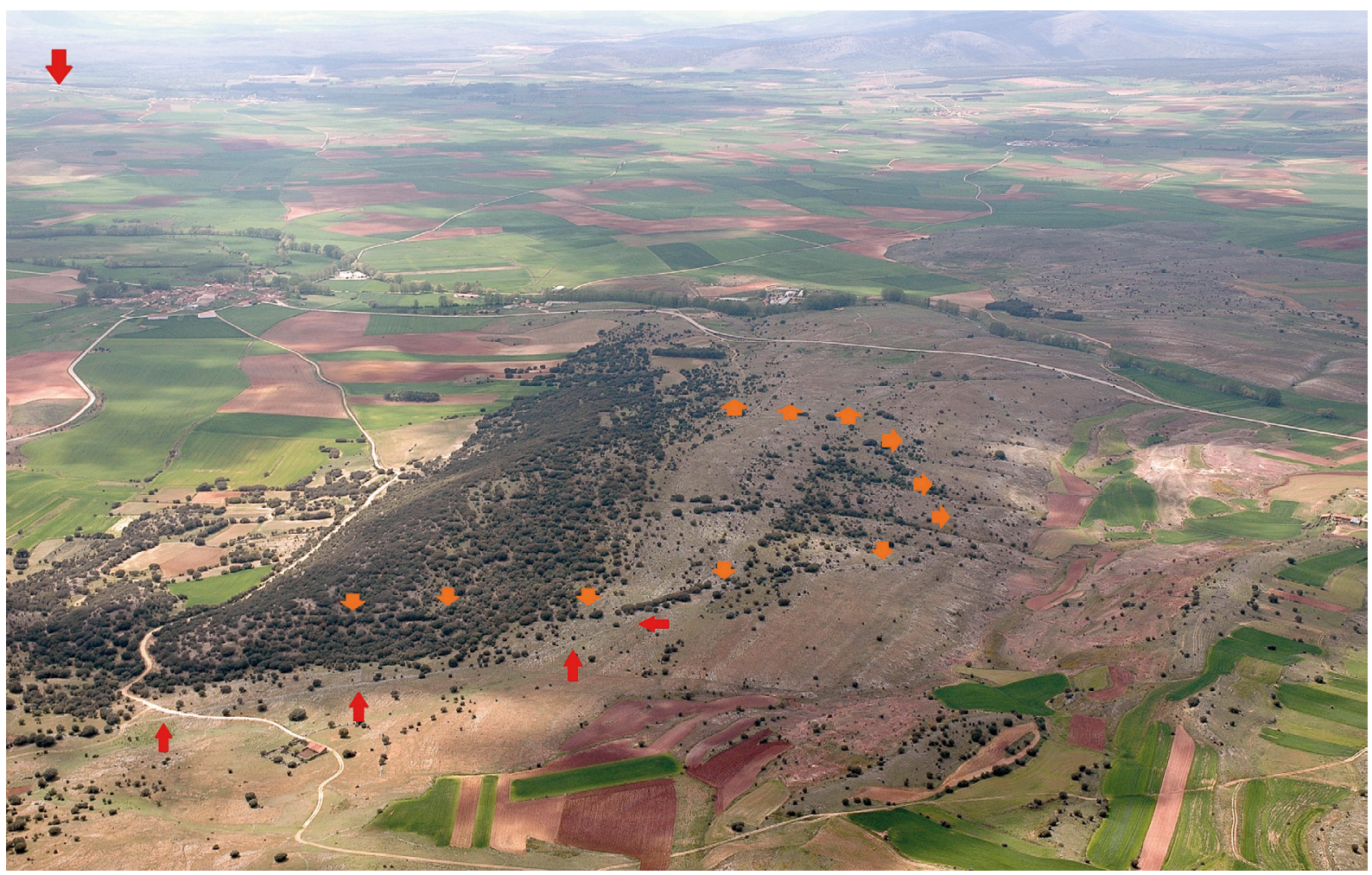

Figura 14. Indicación de la muralla oriental y septentrional del Campamento Ill y del Anexo sobre fotografía aérea de F. Didierjean de Renieblas. Al fondo, indicada mediante una flecha la posición de Numancia

Figure 14. Aerial view of La Gran Atalaya de Renieblas with indications of the eastern and northern defences of Camp III and Annexe, with the position of Numantia indicates with the red arrow (aerial photograph of F. Didierjean with modifications)

ex novo para el resto de las tropas de su ejército, siguiendo la misma estructura que luego aplicaría en los campamentos y fuertes que formaron el cerco de Numancia, en particular los más grandes, Castillejo y Peña Redonda. El análisis comparativo de Dobson al respecto no deja lugar a dudas respecto a dichas semejanzas. Solo así podría explicarse la convivencia de dos recintos aparentemente separados por un periodo de veinte años, y se reforzaría la idea de la incuestionable ocupación escipiónica de Renieblas (figura I4).

No cabe duda que planteamos aquí una hipótesis de partida, una propuesta abierta cuyo planteamiento que debe ser reforzado con futuras investigaciones ${ }^{10}$.

10 Estando en evaluación el presente trabajo hemos tenido conocimiento de la publicación de un reciente artículo sobre las últimas intervenciones desarrolladas precisamente en Renieblas (Jiménez et alii, 2020). En dicha publicación se propone la sincronía temporal entre el Campamento III y el Campamento II. Este último, al igual que el denominado Campamento VI, sería un anexo del primero. El hallazgo de algunos materiales (denario) y ciertas modificaciones estructurales del Campamento III llevan a los autores a proponer la existencia de dos fases en el mencionado recinto, hipótesis que vendría a refrendar con nuevos datos la que aquí se propone, aunque dichos autores no proponen ninguna secuencia cronológica concreta. 
Bibliografía

\section{Fuentes Clásicas}

Apiano: Appiani. Historia Romana. Prooemium. Iberica. Annibalica. Libyca. Illyrica. Syriaca. Mitbridatica. Fragmenta. I. Trad. P. Viereck y A.G. Ross. Ed. Teubner 1939 (Ed. 1962). Leipzig.

Apiano: Apiano. Historia Romana. Trad. A. Sancho Royo. Ed. Gredos. Madrid, 1980.

Aulo Gelio: Noches áticas. Trad. F. Navarro y Calvo. Ed. Austral. Buenos Aires, 1952.

\section{Genera}

Breuer, P., Luik, M. y Müller, D. (I999): “Zur Wiederaufnahme archäologischer Forschungen in den römischen Lagern bei Renieblas (Prov. Soria)". Madrider Mitteilungen, 40: I25-I45.

Capalbo, A. (1996): Celtiberia. Un estudio de fuentes literarias antiguas. Zaragoza.

Cordero, T., Cerrillo, E.y Pereira, C. (20I7): “Detección de un nuevo campamento romano mediante tecnología LiDAR en las inmediaciones de Mérida". Sagvntvm, 49: 197-20I. https://doi.org/10.7203/sagvntvm.49.10025

Costa García, J.M.y Fonte, J. (2017): "Scope and limitations of airborne LiDAR technology for the detection and analysis of Roman military sites in Northwest Iberia”. En V. Mayoral Herrera, C. Parcero-Oubiña y P. Fábrega-Álvarez (eds.): Archaeology and Geomatics. Harvesting the benefits of 10 years of training in the Iberian Peninsula (2006-2015). Leiden: 57-73.

Crawford, M.H. (1974): Roman Republican Coinage. Cambridge.

Dobson, M. (2008): The Army of the Roman Republic. The second century BC, Polybius and the camps at Numantia, Spain. Exeter. https://doi.org/Io.3764/ ajaonlineII33.erskine

Dobson, M. y Morales Hernández, F. (2008): "Monedas inéditas de los campamentos romanos republicanos del cerco de Escipión y de la Gran Atalaya de Renieblas, y algunas consideraciones cronológicas sobre el campamento $\mathrm{V}$ de Renieblas". Archivo Español de Arqueologia, 81: 213-228. https:// doi.org/ıo.3989/aespa.2008.v8I.47
Dobson, M. y Morales, F. (2010): "Coinage from the Roman Republican camps at Numantia and Renieblas (Prov. Soria), with a discussion of some recently found unpublished coins and the dating of Lager V at Renieblas". Madrider Mitteilungen, 51: 323-347.

Fabricius, E. (I9II): "Über die Ausgrabungen in Numantia“. Archäologischer Anzeiger: 370-382.

Forlin,P.(20I2): "Airborne LiDAR data analysis within the Alpine landscapes of Trentino: a methodological approach". Post-Classical Archaeologies, 2: 247-68.

García-Bellido, M.P. (1986): "A Hub from ancient Spain”. Numismatic Chronicle, I46: 76-84.

Gómez-Pantoja, J. y Morales, F. (2002): "Sertorio en Numancia: una nota sobre los campamentos de la Gran Atalaya”. En A. Morillo (coord.): Arqueologia Militar Romana en Hispania. Anejos de Gladius 5, Madrid: 303-310. https://doi.org/ro.3989/ gladius.2010.0003

Gómez-Pantoja, J. y Morales, F. (2008): "Los etolios en Numancia". Salduie, 8: 37-58.

González Fernández, J. (1996): "P. Cornelius Scipio Aemilianus et Aetoli”. Athenaeum, 84: I43-156.

Haeberlin, E.J. (1929): "Die Münzen aus der Stadt Numantia, den Lagern des Scipio und den Lagern bei Renieblas", en A. Schulten: Numantia IV.Die Lager bei Renieblas. München.

Hesse, R. (2010): "LiDAR-derived Local Relief Models. A new tool for archaeological prospection". Archaeological Prospection, I7: 67-72.

Hildebrandt, H. J. (1979): "Die Römerlager von Numantia. Datierung anhand der Münzfunde”. Madrider Mitteilungen, 20: 238-27I.

Jiménez, A. (20I4): "Ejército y moneda en Numancia. El campamento III de Renieblas". En F. Cadiou y M. Navarro (eds.): La guerre et ses traces. Conflicts et sociétés en Hispanie à l'époque de la conquête romaine (III ${ }^{e}-I^{e r}$ s. a. C.). Memoires, I5. Bordeaux: 369-393. https://doi.org/Io.IoI7/sI04775940007287I

Jiménez, A., Bermejo, J., Liceras, R., Moreno, F. y Tardio, K. (2018): "Archaeological perspectives on the siege of Numantia. The new fieldwork Project at the Roman camps at Renieblas (Spain, $2^{\text {nd }-\mathrm{I}^{\text {st }}}$ centuries BC". Confict Archaeology. Materialities of Collective Violence from Prehistory to Late Antiquity, Abingdon-New York: II5-126. https://doi.org/IO.4324/978131514477I-II 
Jiménez, A., Bermejo, J., Valdés, P., Moreno, F. y Tardio, K. (2020): "Renewed work at the Roman camps at Renieblas near Numantia $\left(2^{\text {nd }}-\mathrm{I}^{\text {st }} \mathrm{c}\right.$. B.C.)“. Journal of Roman Archaeology, 33: 4-35.

Jimeno Martínez, A. (2002): "Numancia: campamentos romanos y cerco de Escipión", Archivo Español de Arqueologia, 75: 159-176. https://doi. org/I0.3989/aespa.2002.v75.I33

Jimeno Martínez, A. y Chaín Galán, A. (2017): La guerra numantina: cerco y conquista de Numancia. Valladolid.

Jimeno Martínez, A. y Martín Bravo, A. (1995): "Estratigrafía y numismática; Numancia y los campamentos”. En M.P. García-Bellido M. y R. Sobral Centeno (eds.): La moneda hispánica. Ciudad y territorio. Anejos de Archivo Español de Arqueología, I4: 180-19o. https://doi.org/Io.3989/ aespa.1995.v68.402

Kovaks, K. et alii (20I2): "Utilization of airborne LIDAR dataset in GIS enviromnent for prospection of archaeological sites in high alpine regions", Archeologia e Calcolatori, 23: 15I-I64.

Lechuga Galindo, M. (I986): Tesorillos de moneda romano-republicana de la región de Murcia. Murcia.

Luik, M. (2002a): Die Funde aus den römischen Lagern um Numantia im Römisch-Germanischen Zentralmuseum. Mainz.

Luik, M. (2002b): "Die römischen Lager bei Renieblas, Prov Soria (Spanien). Ergebnisse der Vermessungskampagnen 1997-2000”. En Ph. Freeman, J. Bennett, A. T. Fiema y B. Hoffmann (eds.), $L i-$ mes XVIII. Proceedings of the XVIII In International Congress of Roman Frontier Studies (Amman, Jordan, Sept. 2000). BAR International Series Io84 (II). Oxford: $777^{-} 777$.

Marchetti, P. (1978): Histoire économique et monétaire de la Deuxième Guerre Punique. Bruxelles.

Morais, R., Morillo, A. y Adroher, A. (2or6): "Patrones de importación e imitación cerámica en el ámbito militar (siglos II a. C.-I d. C.)". En R. Járrega y P. Berni (eds.): Amphorae ex Hispania: paisajes de producción y consumo, Monografías ex Officina Hispana III. Tarragona: 713-729.

Morales Hernández, F. (2000): "Una reinterpretación de la circunvalación escipiónica de Numancia”. Revista d'Arqueologia de Ponent, 10: 227-24I.
Morales Hernández, F. (2004): "Los campamentos y fuertes romanos del asedio de Numancia". En C. Pérez González y E. Illarregui (coords.): Actas de Arqueología Militar Romana en Europa. Salamanca: 25I-258. https://doi.org/Io.3989/gladius.2010.0003

Morales Hernández, F. (2006): "Circunvallatio of Numantia. Forts and siege Works". en A. Morillo y J. Aurrecoechea (eds.): The Roman Army in Hispania. An Archaeological Guide. León: 249-262.

Morales Hernández, F. (202I): "Comentarios en torno a las dos llegadas de Escipión a Numancia: deconstruyendo a Schulten". Cuadernos de Arqueología de la Universidad de Navarra, 29: 1-58.

Morillo, A. (199I): "Fortificaciones campamentales de época romana en España”. Archivo Español de Arqueologia, 64: 135-190. https://doi.org/Io.3989/ aespa.1991.v64.502

Morillo, A. (2003): "Los establecimientos militares temporales: conquista y defensa del territorio en la Hispania republicana”. En A. Morillo, F. Cadiou y D. Hourcade (eds.): Defensa y territorio en Hispania de los Escipiones a Augusto. Actas coloquio. León-Madrid: 4I-80.

Morillo, A. (2008): "Criterios arqueológicos de identificación de campamentos romanos en Hispania”. Salduie, 8: 73-93.

Morillo, A. (20I4): "Campamentos y fortificaciones tardorrepublicanas en Hispania. 'Calibrando' a Sertorio". En F. Sala y J. Moratalla (eds.): Las Guerras Civiles romanas en Hispania. Alicante:35-49. https:// doi.org/Io.5209/rev_geri.2016.v34.53762

Morillo, A. (2016): "Campamentos y fortificaciones tardorrepublicanas en Hispania. Una nueva línea de investigación en arqueología militar romana”. En J. Pera y J. Vidal (eds.): Fortificaciones $y$ control del territorio en la Hispania republicana. Zaragoza: $\mathrm{I}-5$ I.

Morillo, A. y Adroher, A. (20I4): "Modelos de arquitectura defensiva e implantación territorial de los campamentos republicanos en Hispania". En R. Mataloto, V. Mayoral y C. Roque (eds.): La Gestación de los paisajes rurales entre la protohistoria y el periodo romano. Formas de asentamiento y procesos de implantación. Anejos de Archivo Español de Arqueología, LXX. Mérida: 228-252. 
Morillo, A.y Adroher, A. (20I4b): "El patrón arqueológico de carácter material: un criterio imprescindible de identificación de recintos militares romano-republicanos". Revista Cira Arqueológica,3: 25-43.

Morillo, A., Adroher, A,. Dobson, M. y Martín Hernández, E. (2020): "Constructing the archaeology of the Roman conquest of Hispania: new evidence, perspectives and challenges". Journal of Roman Archaeology, 33: 36-52.

Morillo, A. y Morales Hernández, F. (2015): "Campamentos romanos de la Guerra de Numancia: la circunvalación escipiónica”. En M. Bendala (ed.): Los Escipiones en Hispania. Alcalá de Henares: 275-297.

Morillo, A., Morales Hernández, F.y Durán Cabello, R. (2017): "Schulten y los campamentos romanos republicanos en Hispania: una mirada desde el siglo xxı". En E. Baquedano y M. Arlegui: Schulten y el descubrimiento de Numancia. Alcalá de Henares: 175-200.

Morillo,A., Rodríguez Martín, G., Martín Hernández, E. y Durán, R. (20II): “The Roman Republican battlefield at Pedrosillo (Casas de Reina, Badajoz, Spain). New research (2007)". Conimbriga, L: 59-78. https://doi.org/Io.I4195/I647-8657_50_3

Morillo, A. y Sala Sellés, F. (20r9): "The Sertorian Wars in the conquest of Hispania: from data to archaeological assesment. En A.P. Fitzpatrick y C. Haselgrove (eds.): The Archaeology of Caesar in Britain and Gaul. New archaeological perspectives. Oxford-Philadelphia: 49-72.

Opitz, R. y Cowley, D.C. (eds.) (2013): Interpreting archaeological topography: airborne laser scanning, ${ }_{3} \mathrm{D}$ data and ground observation. Oxford.

Orejas, A. (1995): Del «marco geográfico» a la Arqueología del paisaje. La aportación de la fotografía aérea. Madrid.

Pamment Salvatore, J. (1996): Roman Republican Castrametation. A Reappraisal of historical and Archaeological sources. BAR International Series 630. Oxford. https://doi.org/Io.3086I/9780860548126

Picarreta, F. (1987), Manuale di fotografia aerea: uso archeologico. Roma.

Principal, J. (2000): "Vajilla de barniz negro en los campamentos del Cerco de Numancia (Garray, Soria)". En X. Aquilué et alii (coords.), La ceràmica de vernis negre dels segles II i I aC. Centres productors mediterranis $i$ comercialització a la Península Ibèrica. Mataró: 269-279.
Principal, J. (2013): "Cuando Arqueología e Historia se dan la mano: Cartago y Numancia, dos buenos referentes". En A. Ribera (ed.): Manual de cerámica romana. Del mundo helenístico al imperio romano. Alcalá de Henares: 332-356.

Romero Carnicero, M.V. (I990): "Lucernas republicanas de Numancia y sus campamentos". Boletín del Seminario de Estudios de Arte y Arqueologia, 56, 257-296.

Sánchez-Palencia, F.J. y Currás, B.X. (2015): "Campamentos romanos en zonas mineras del cuadrante noroeste de la Península Ibérica”. En J. CaminoMayor, E. Peralta-Labrador y J.F. Torres-Martínez (coords.): Las Guerras Astur-Cántabras. Oviedo: $273-283$.

Sanmartí, J. (1985): "Las ánforas romanas del campamento numantino de Peña Redonda (Garray, Soria)". Ampurias, 47: 130-16I.

Sanmartí,E. (1992): "Nouvelles données sur la chronologie du camp de Renieblas $V$ à Numance (Soria, Castilla-León, Espagne)". Documents d'Archéologie Méridionale, I2: 4I7-430.

Sanmartí, E. y Principal, J. (1997): "Las cerámicas de importación, itálicas e ibéricas, procedentes de los campamentos numantinos". Revista d'Arqueologia de Ponent, 7: I-39.

Sanmartí, E. y Principal, J. (1998): “Cronología y evolución tipológica de la Campaniense A del siglo II a.C.: las evidencias de los pecios y de algunos yacimientos históricamente fechados". En J. Ramon et alii (eds.), Les faccies ceràmiques d'importació a la costa ibèrica, les Balears i les Pitiüses durant el segle III aC i primera meitat del segle II aC. Arqueomediterrània, 4. Barcelona: 193-215.

Santapau, C., Herreros, C. y Sanfeliu, D. (2003): "Vajilla y alimentación en la guerra de Numancia. Su reflejo en las fuentes literarias". Iberia, 6: 7-23.

Schulten, A. (I9II): "Ausgrabungen in Numantia". Archäologischer Anzeiger: 3-39.

Schulten, A. (1914): Numantia I: Die Keltiberer und ibre Kriege mit Rom. München.

Schulten, A. (1927): Numantia. Die Ergebnisse der Ausgrabungen 1905-19I2. III, Die Lager des Scipio. München.

Schulten, A. (1928): "Römische Lager in Spanien". Forschungen und Fortschritte, 4: 4I-43. 
Schulten, A. (1929): Numantia IV: Die Lager bei Renieblas. München.

Schulten, A. (1937): Fontes Hispaniae Antiquae, 4. Las guerras de 154-72 a. C. Barcelona.

Schulten, A. (1945): Historia de Numancia. Barcelona. Štular, B., Kokali, Ž., Oštir, K. y Nuninger, L. (2012): "Visualization of Lidar-Derived Relief Models for Detection of Archaeological Features". Journal of Archaeological Science, 39 (II): 3354-3360.
Wilson, D.R. (1982): Air photo interpretation for archaeologist. London.

Zakšek, K., Oštir, K. y Kokalj, Z. (20II): "Sky-View Factor as a Relief Visualization Technique”. Remote Sensing, 3: 398-415. 